\title{
DRIVING FORCES \& CAHLLENGES FOR CONSTRUCTING SKYSCRAPERS
}

\author{
Sofia Ayad*, Ghada Farouk Hassan and Yehia Serag \\ Urban Design And Planning Dep. ,Faculty Of Eng., Ain Shams, University, Cairo, Egypt \\ *Corresponding Author E-mail: Sofia.Dawoud@Fue.edu.eg
}

\begin{abstract}
:
Vertical urbanism have become one of measuring criteria for civilization and urban development; as a result most countries around the world are competing for having the Highest skyscraper.

Hence, this study aims to find the driving forces for constructing skyscrapers. Thus, the methodology implemented in this research will follow a descriptive approach by reviewing the literarture review related to the emergence and growth of skyscrapers, then the research will go through the driving forces for constructing such type of buildings and the challenges.

Finally, The results concluded that building skyscrapers become a must to cope with the development and simulate globalization, to face the increased population and to regenerate the urban centers.Moreover, constructing skyscrapers shows great potentials in the investment returns by save more places for social and cultural activities, especially with the increased land prices,as well as the various environmental related issues.
\end{abstract}

KEY WORDS: Skyscrapers, Challenges, Driving Forces, Environmental Impact, Economic

$$
\begin{aligned}
& \text { الافافع وراء بناء ناطحات السحاب و التحديات التى تواجهها }
\end{aligned}
$$

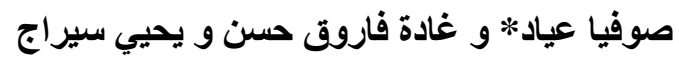

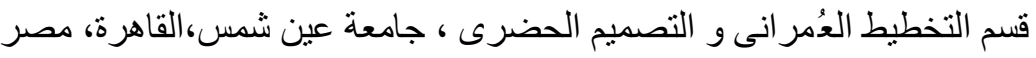

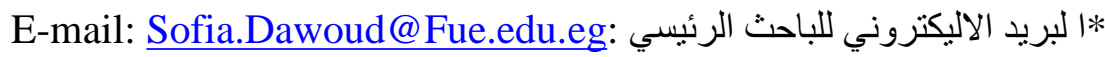

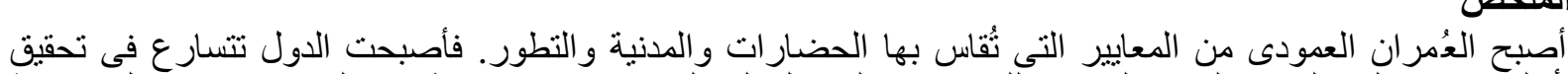

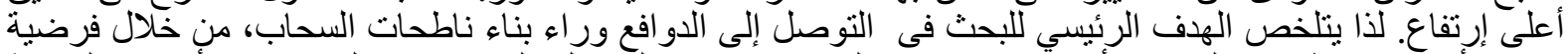

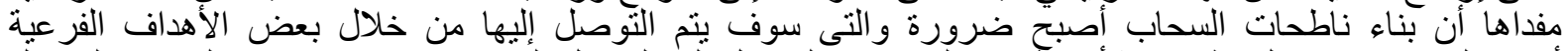

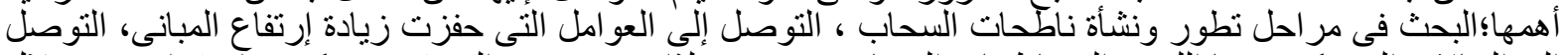

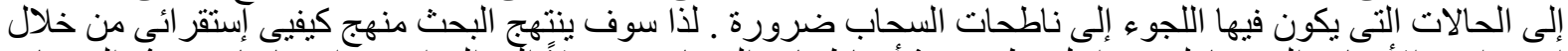

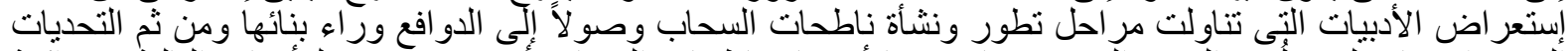

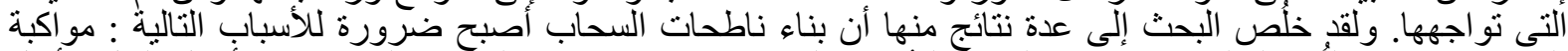

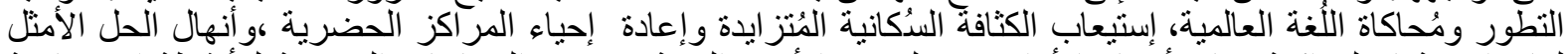

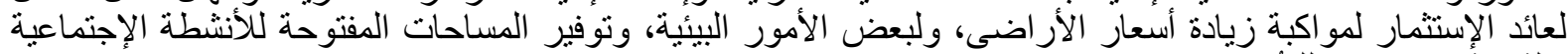

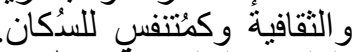

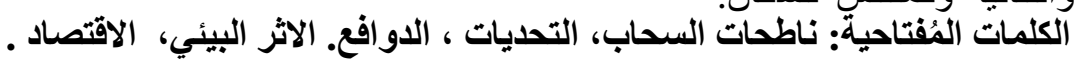

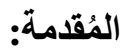

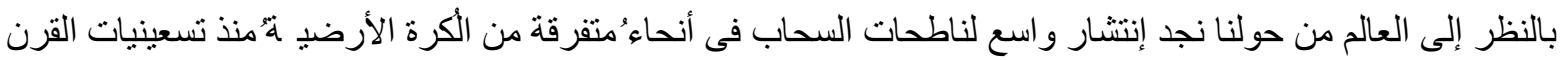

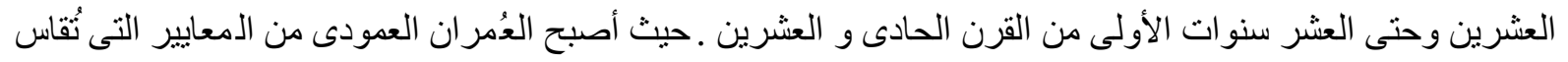




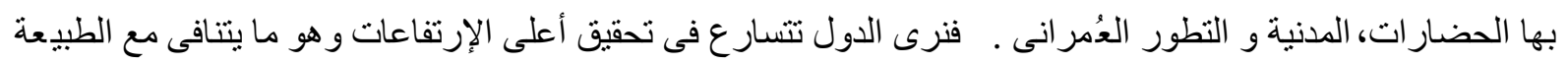

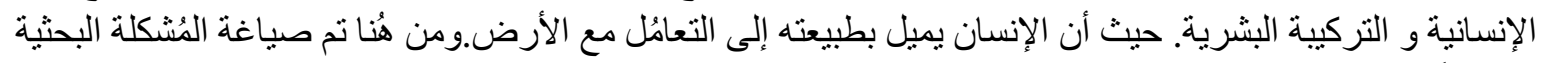

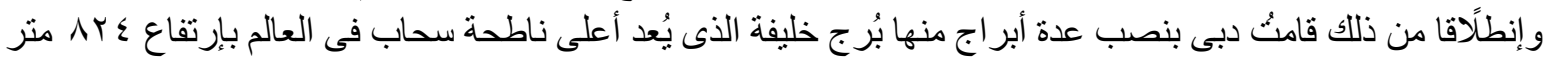

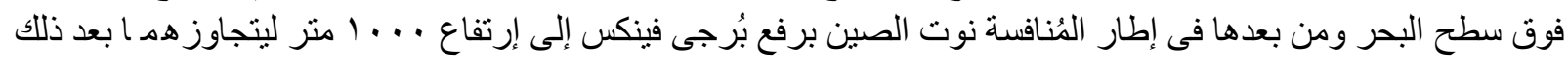

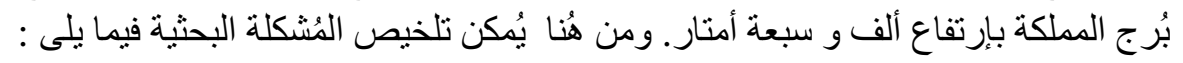

المُشكلة البحثية:

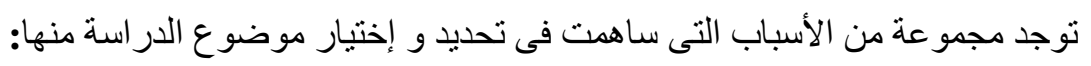
-

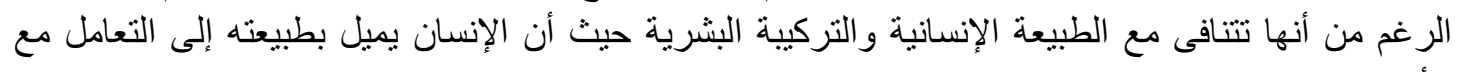

- إنتشار الجدل حول ناطحات السحاب ما بين مؤيديدن ومُعارضين.

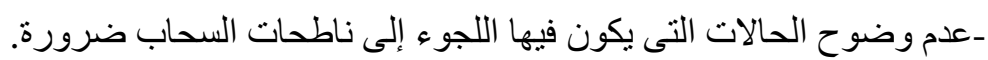

الفرضية:

إنطلق البحث من فرضية مفداها ان "بناء ناطحات السحاب أصبح ضرورة".

أهداف البحث :

يتلخص الهذف الرئيسي للبحث فى التوصل إلى إلى الدوافع وراء بناء و إنتشار ناطحات السحاب.و التى سوف يتم

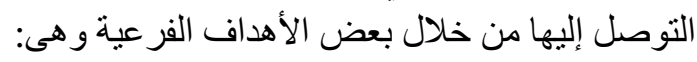

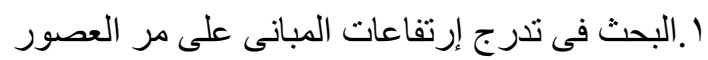

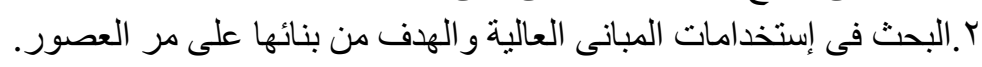

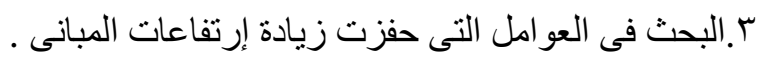

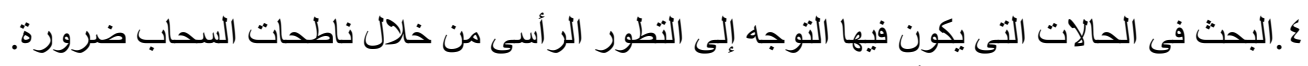

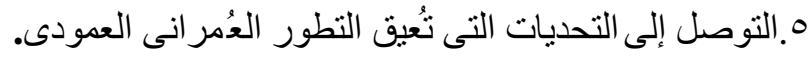

\section{منهجية البحث :}

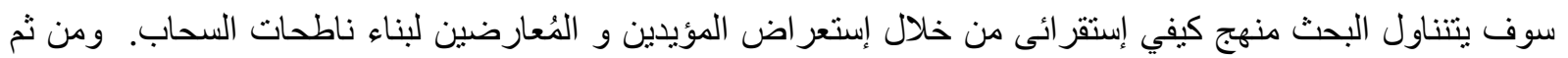

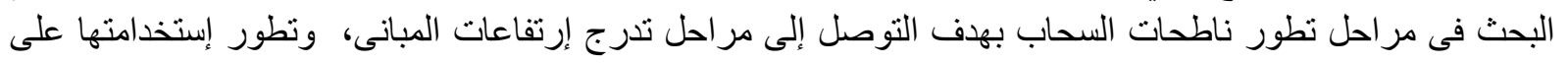

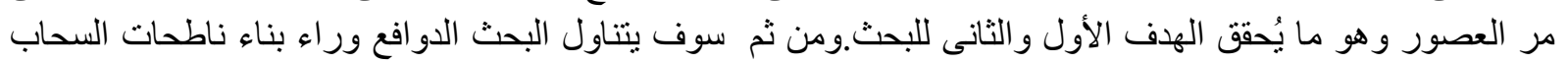

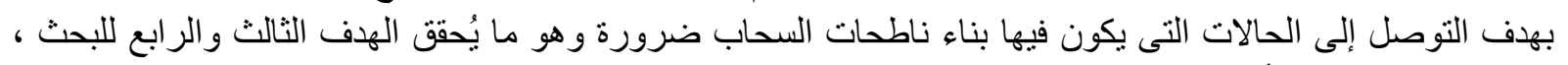

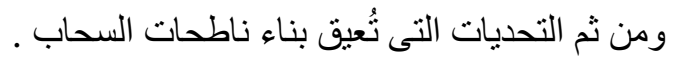
التعريف ناطحات السحاب:

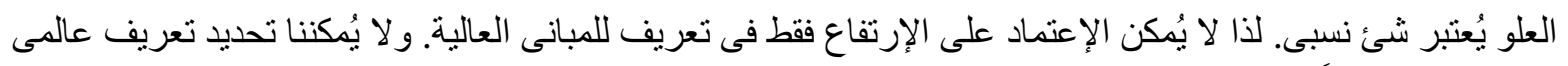

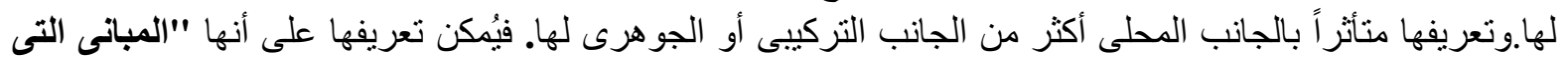

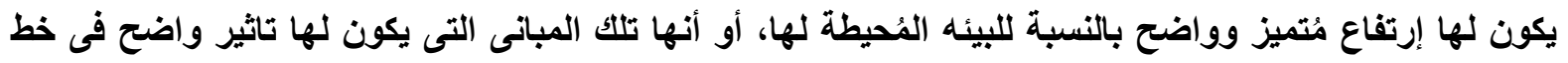

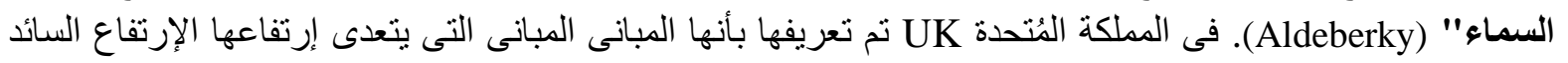

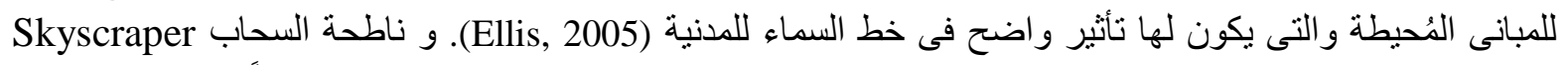

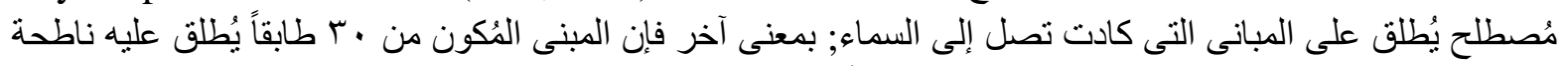

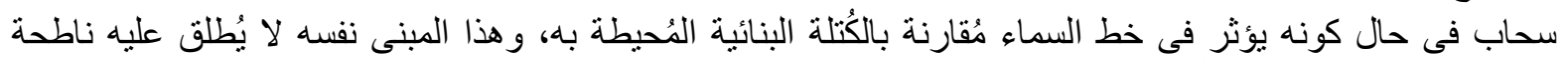

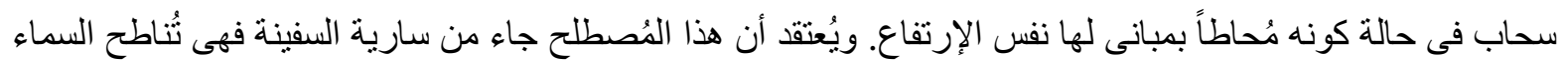

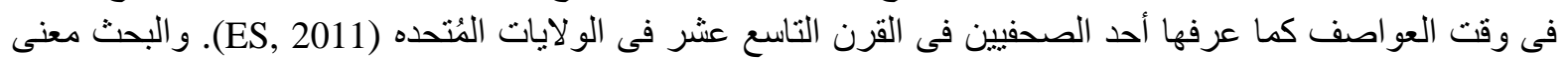
بناطحات السحاب فهى محط أنظار العالم في الآونة الأخيرة.

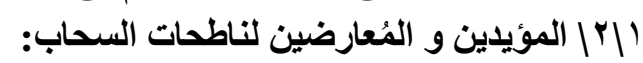

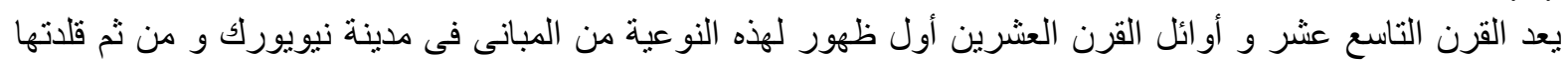

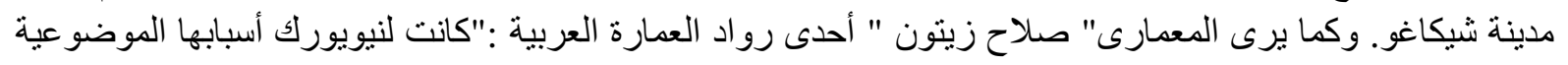

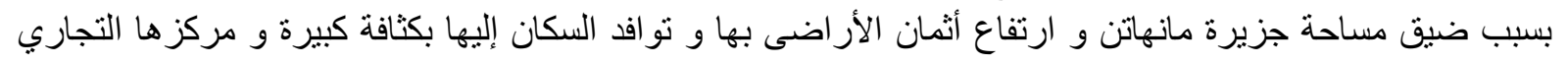


المتعاظم مما جعل المستثمرين يلجأون إلى استغلال أراضى البناء أكبر استغلال. أما مدينة شيكاغو فلم يكن هناك أي مبرر

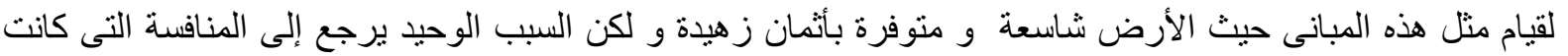

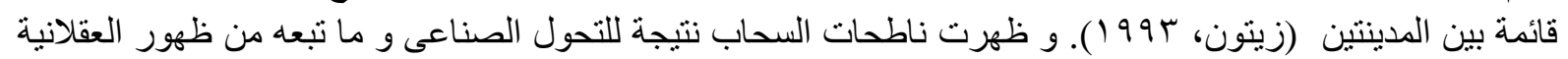

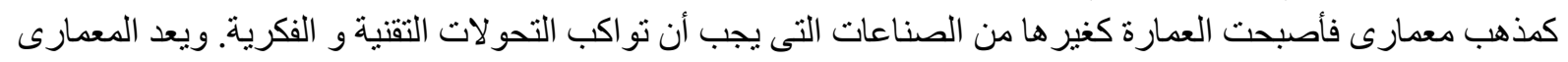

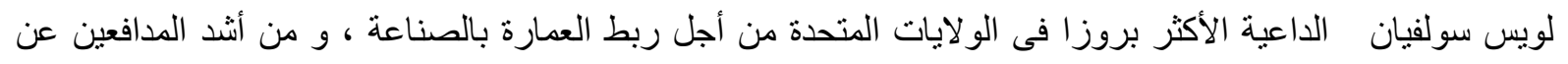

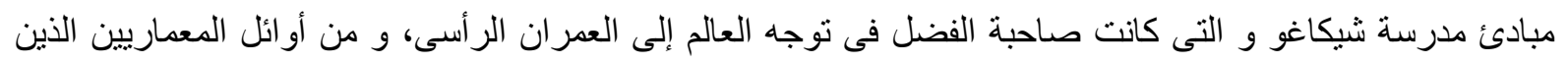

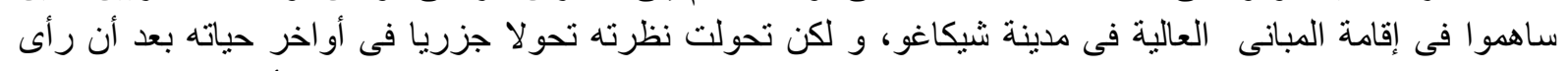

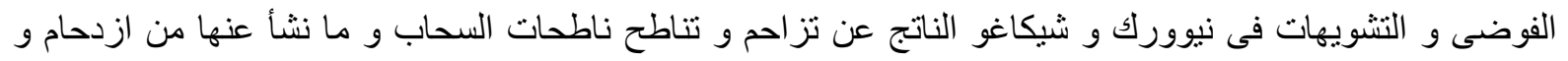

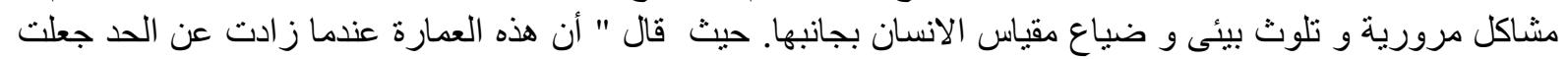

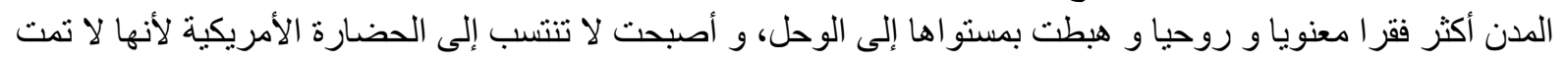

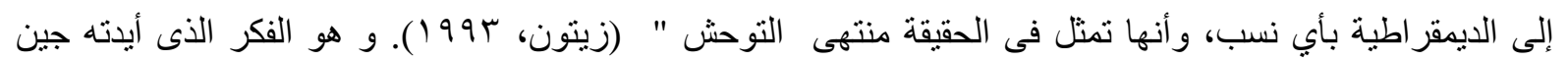

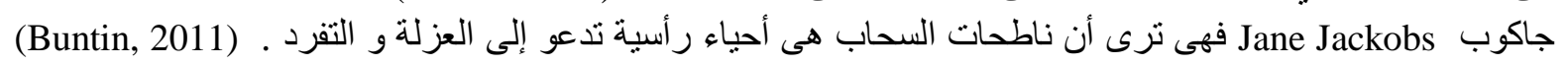

(Ali K. , 2011)

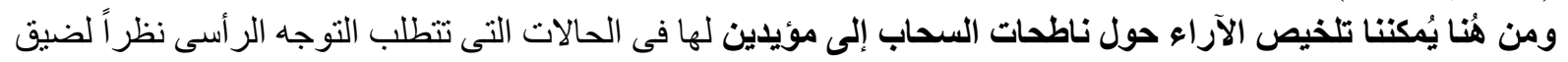

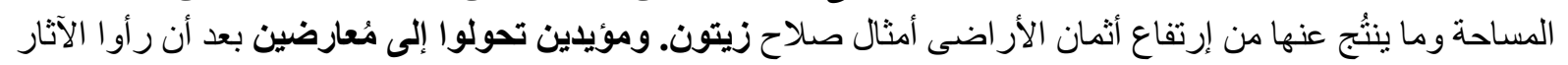

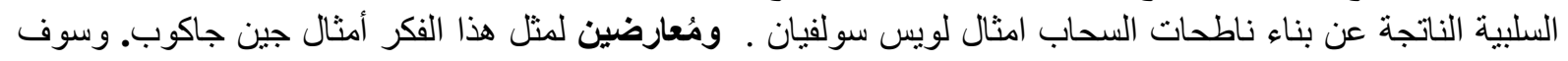

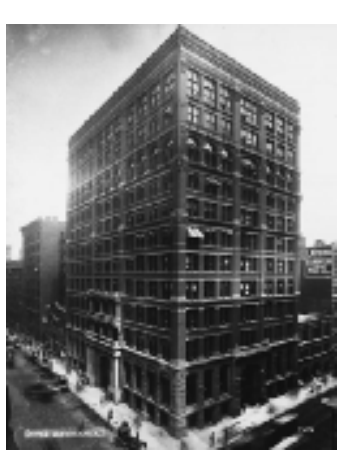

Home رسم توضيحي ا : مبنى التول Insurance ناطحة سحاب فى العالم

Collection of the Chicago Historical Society (ICHi.(00990)

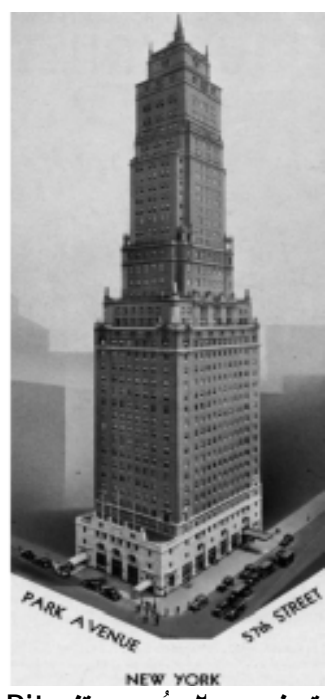

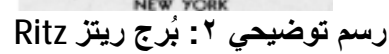

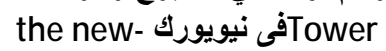
York Historical Society

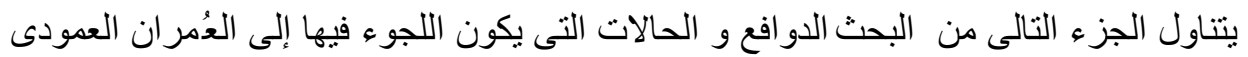
هو الحل الأمثل. التاتاريخ تطور المبانى العالية و ناطحات السحاب:

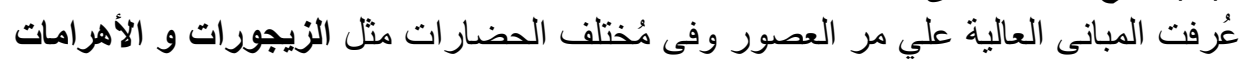

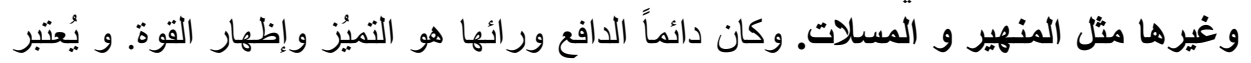

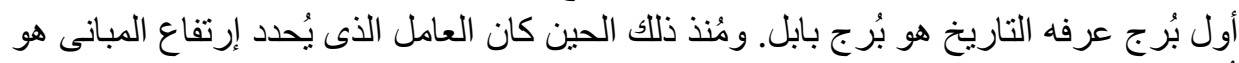

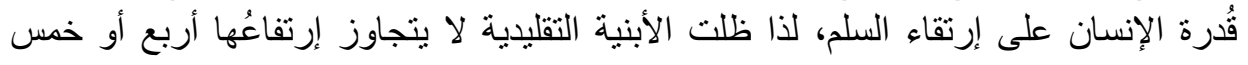

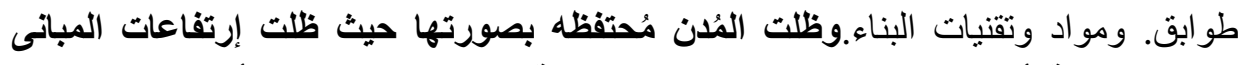

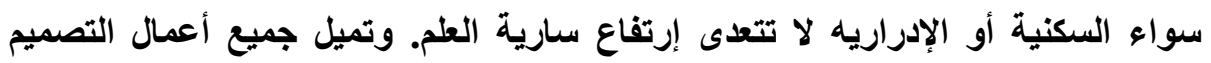

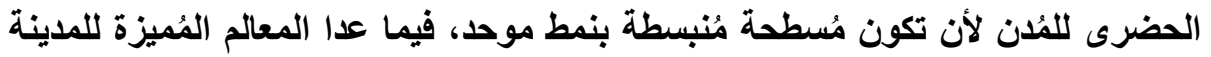

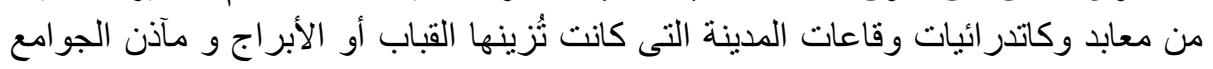

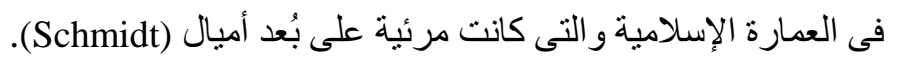

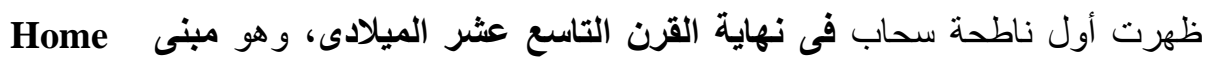

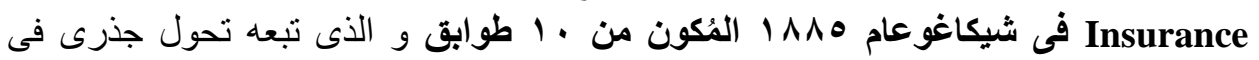

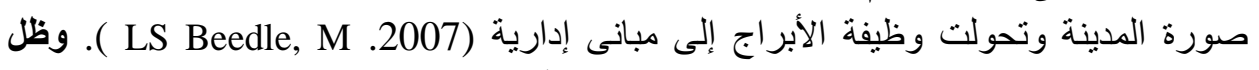

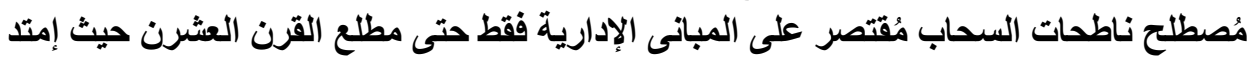

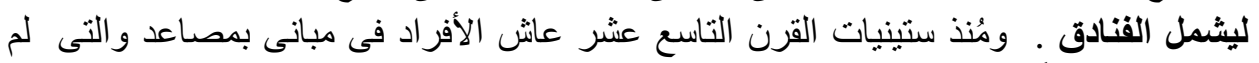

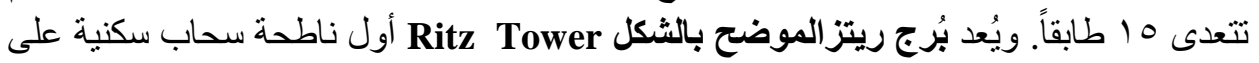

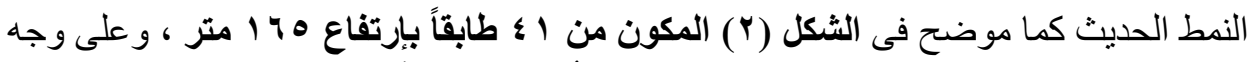

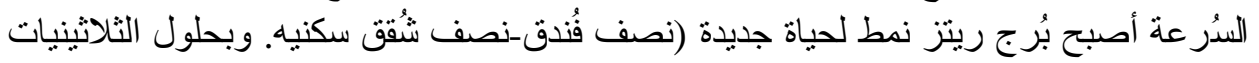

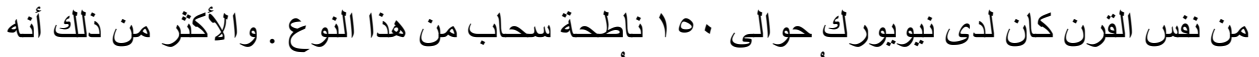

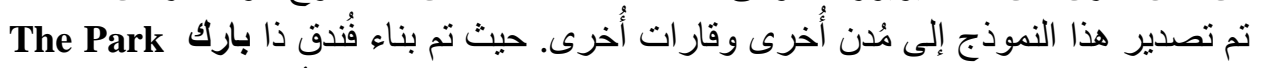

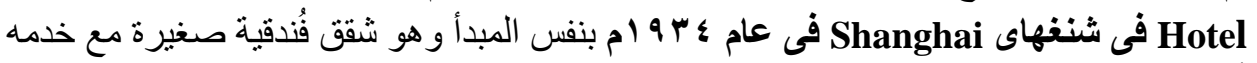

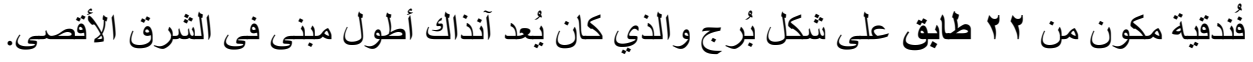

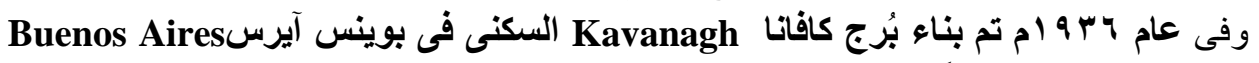

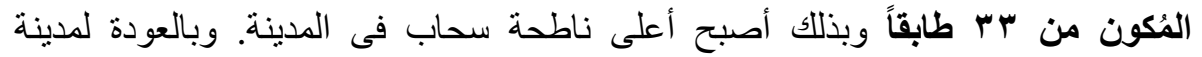

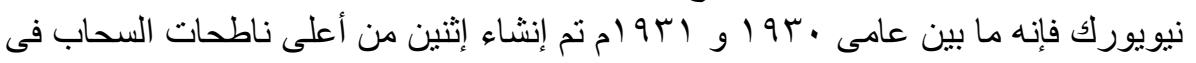


العالم ألا و هما مبنى كريسلر Chrysler Building المُكون من VV طابقاً بإرتفاع 9 الب م، ومبنى إمبر ستيت Empire State Building

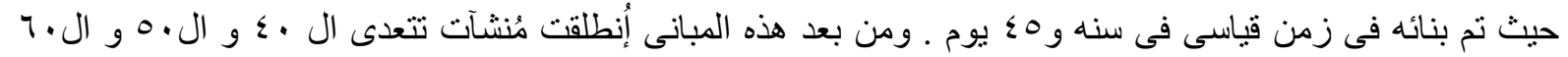

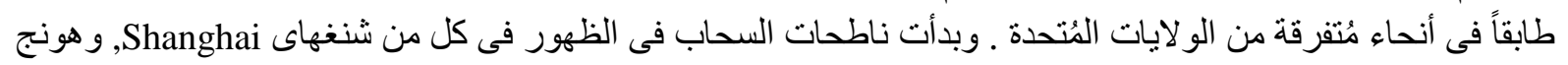

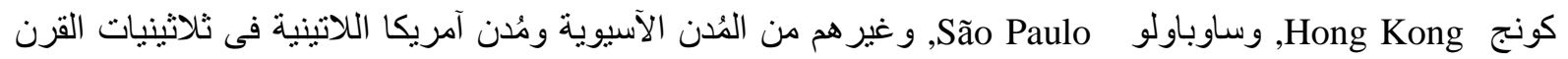

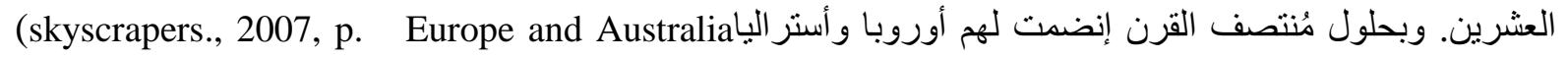

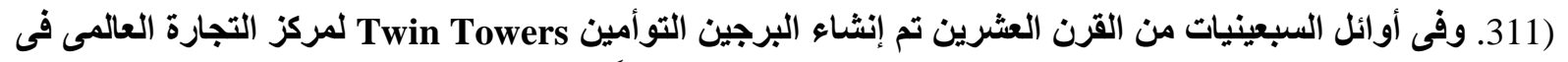

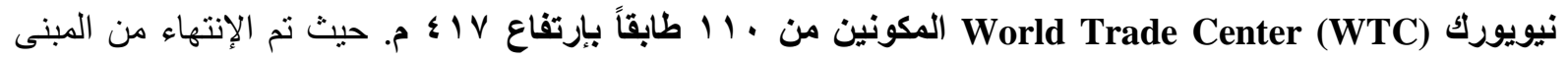

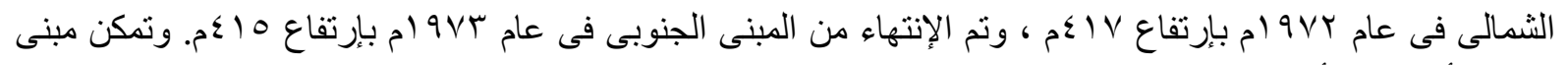

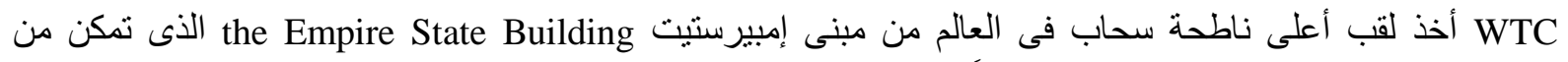

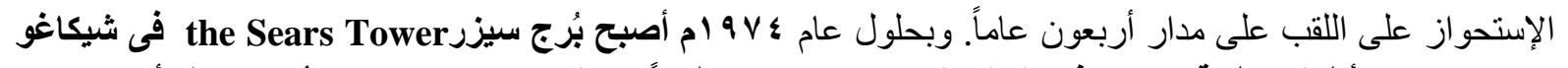

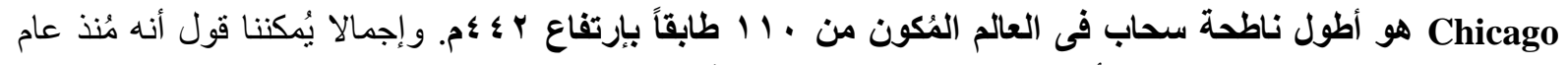

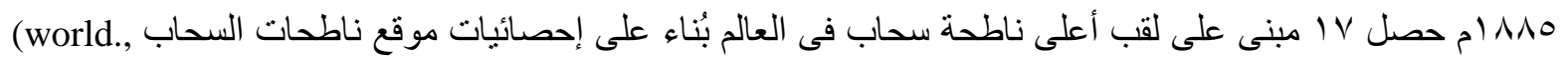

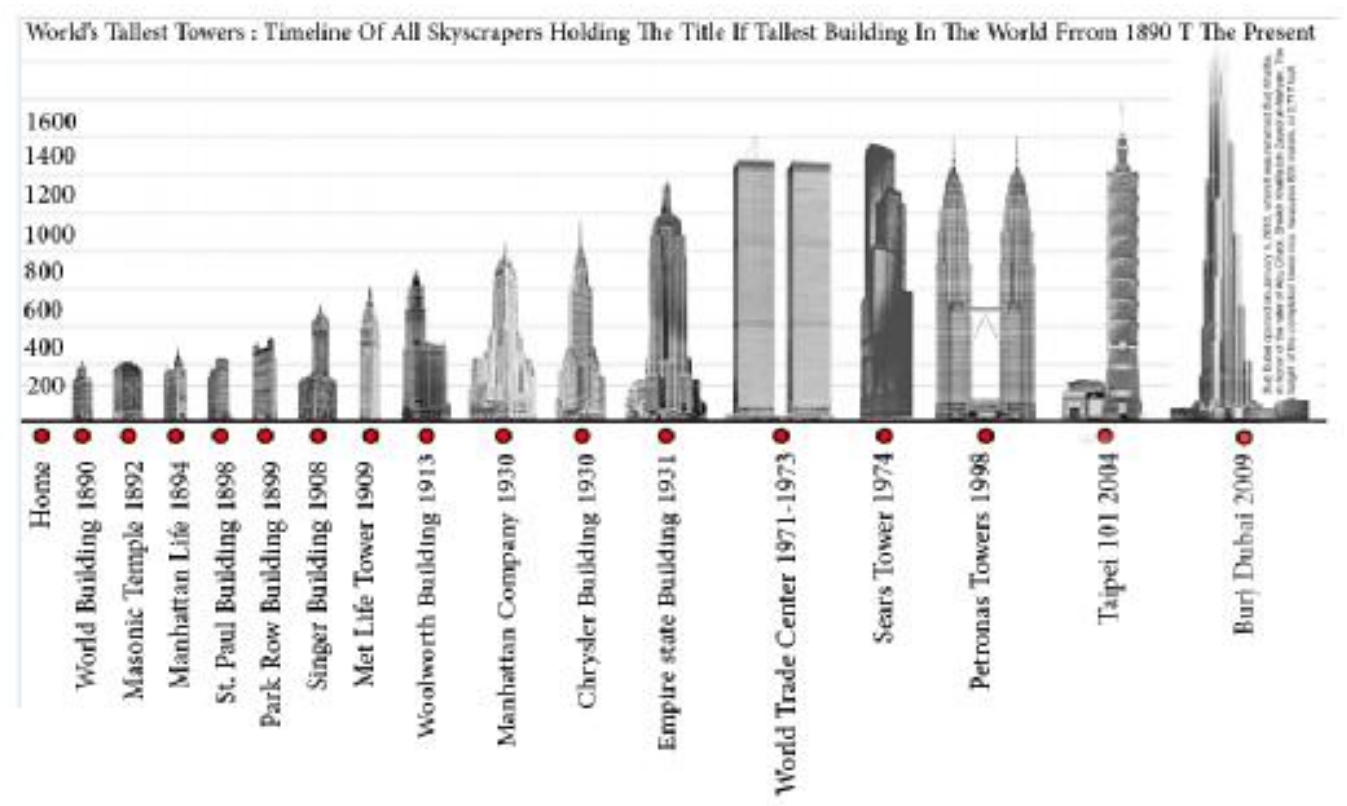

رسم توضيحي؟ّ: المبانى الحائزه على لقب أعلى ناطدة سحاب فى العالم على مر التاريخ

https://www.skvscraper.org/TALLEST TOWERS/tallest.htm

وفى عام rو إم قام مجلس المبانى العالية والموطن الحضرى Council on Tall Buildings and Urban Habitat

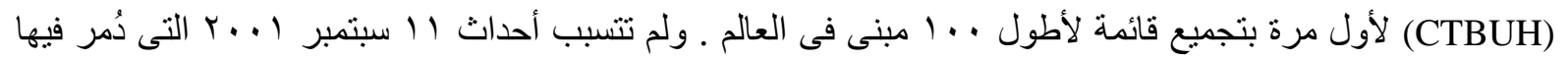

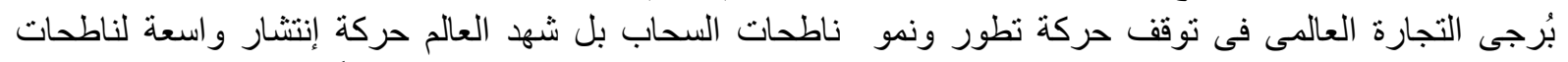

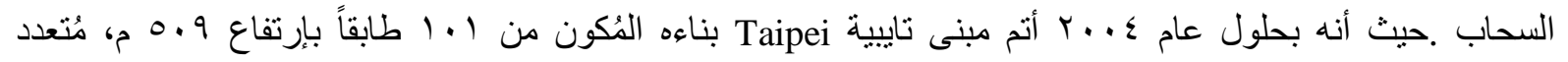

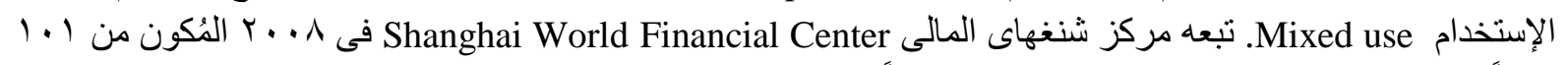

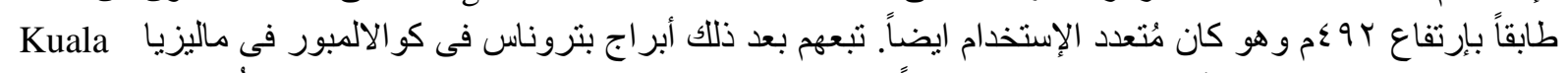
بالزجاج. Lumpur, Malaysia

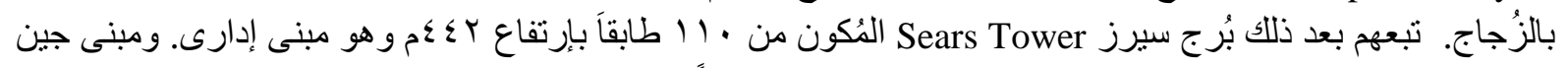

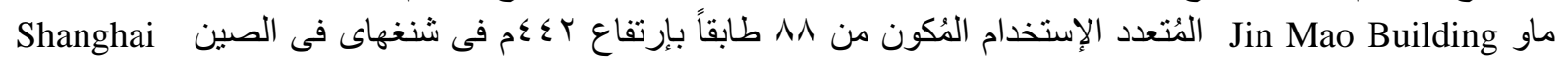

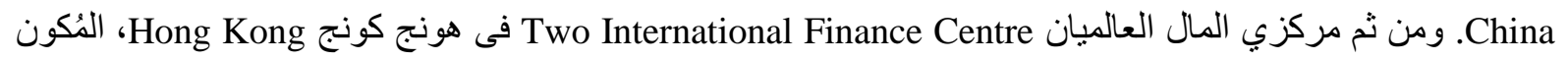

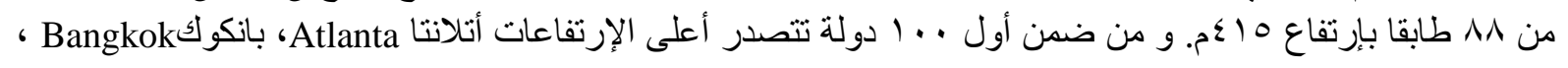


شارلوت Charlotte، شيكاغو Chicago ، تشونغتشينغ Chongqing، كليفلاند Develand، دالاس Dallas، الدوحة

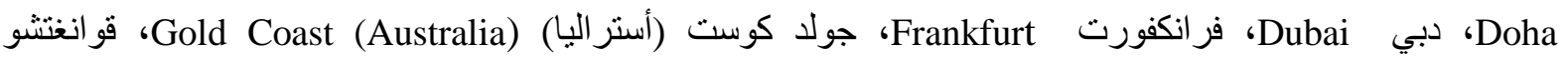
Guangzhou

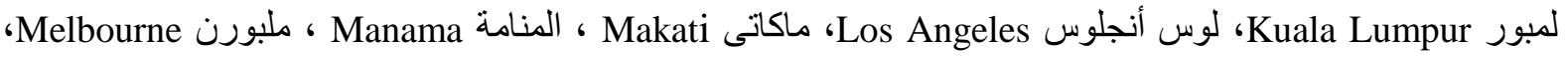

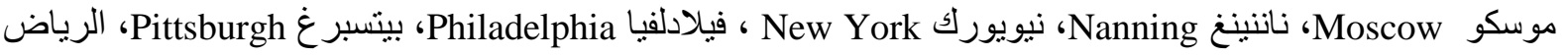

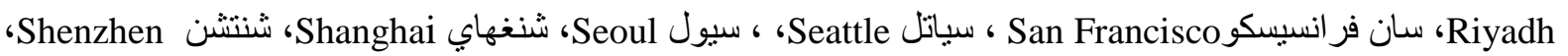

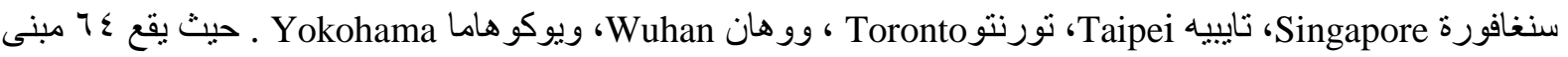

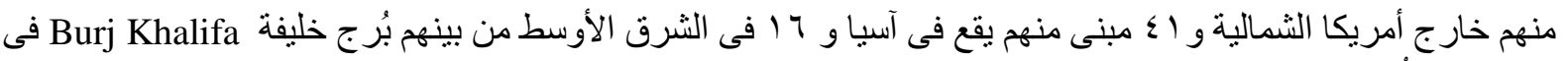

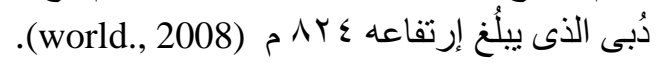

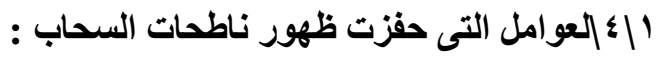

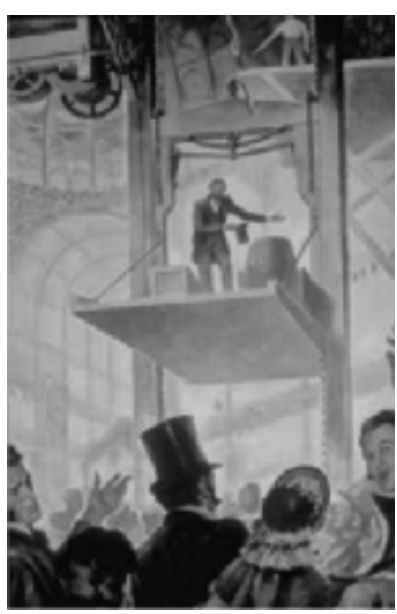

رسم توضيحي؛: إليشا غريفز يقوم

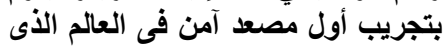

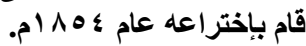

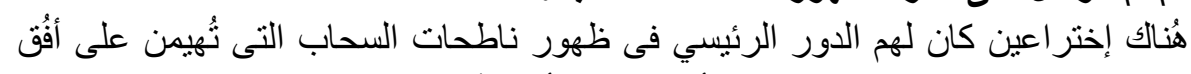

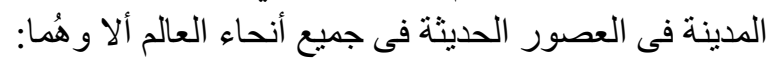

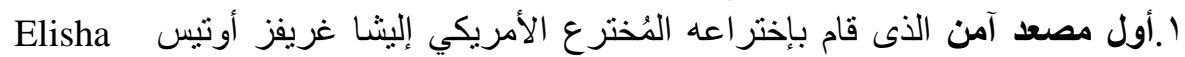
و Graves Otis

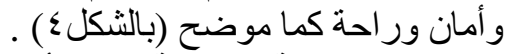

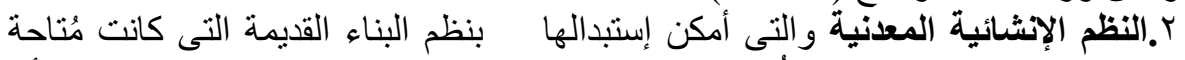

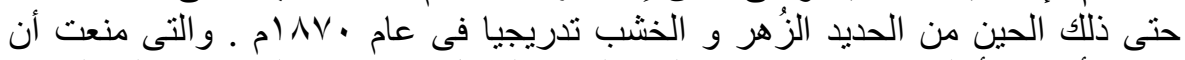

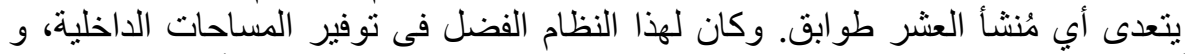

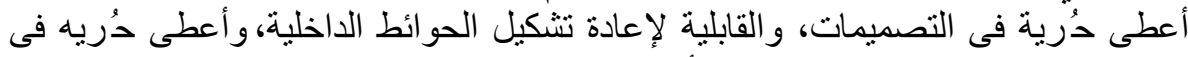
الفتحات على الوجهات الخارجية مما أدى إلى إمكانية زيادة الإضائه الطبيعية داخل المبلة المبانى

(Dupré, 2001)

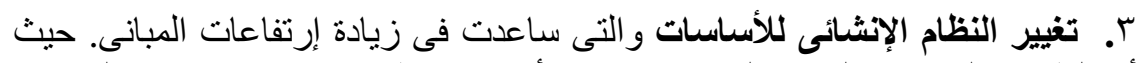

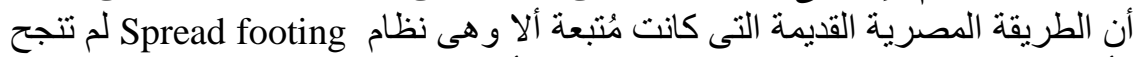

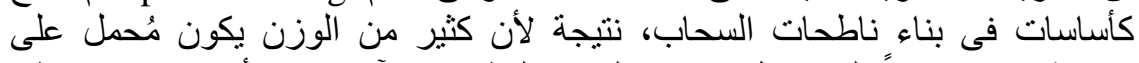

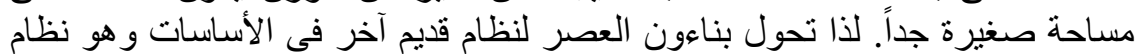

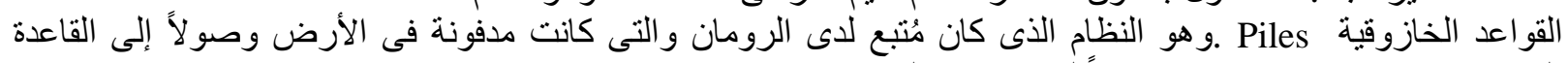

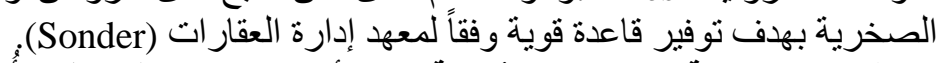

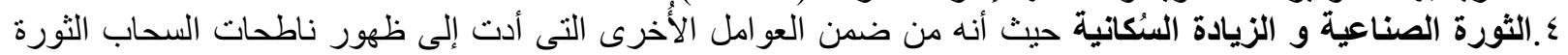

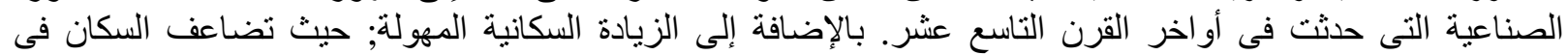

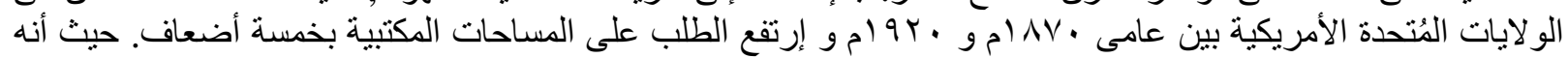

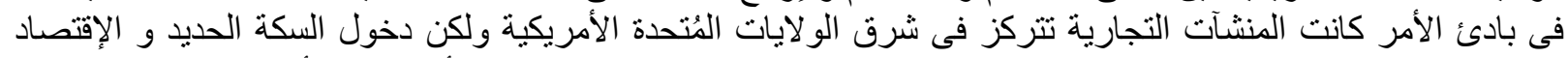

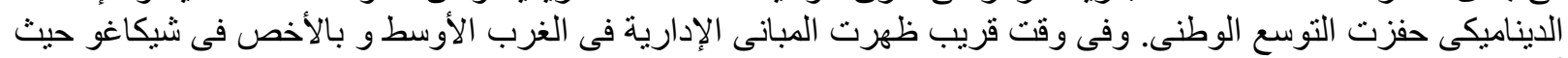

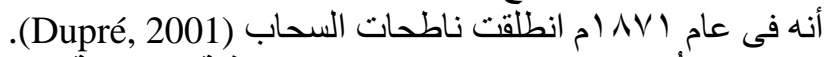

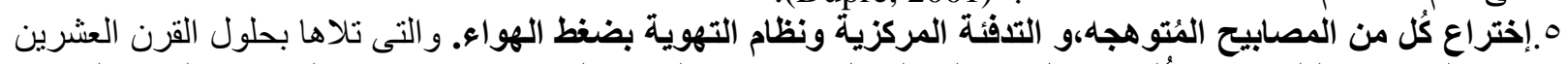

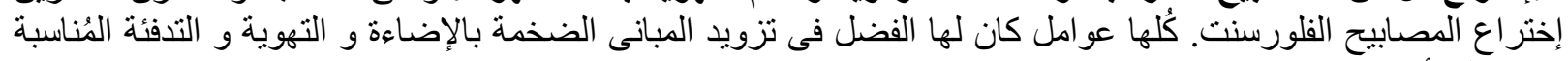

ما جعلها أكثر راحة (Seabrook, 2001).

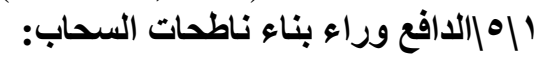

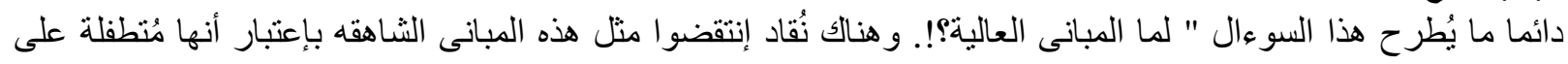

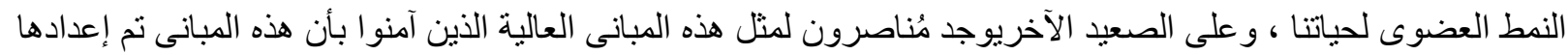

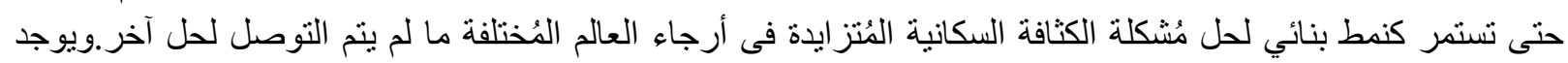
العديد من الأسباب التى أدت إلى نشأة هذا النوع من المبانى وتطور ها حتى أصبحت على على شكلهاء العها الحالى وفيما يلى دراسة

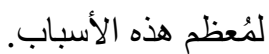

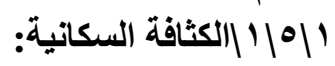

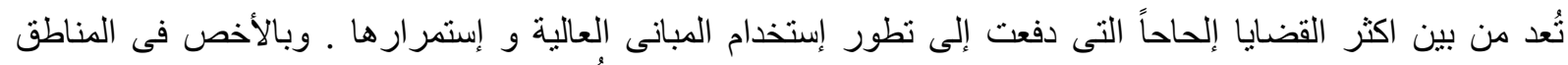

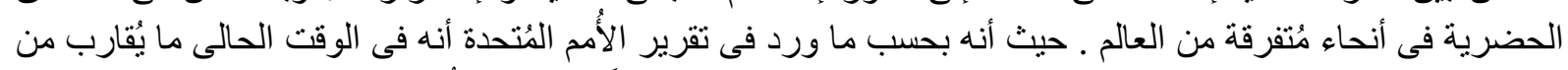

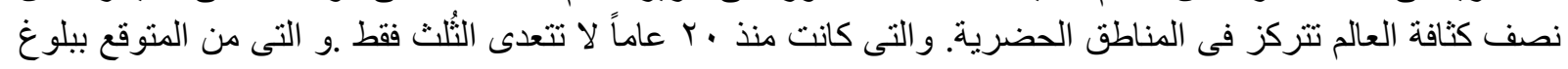




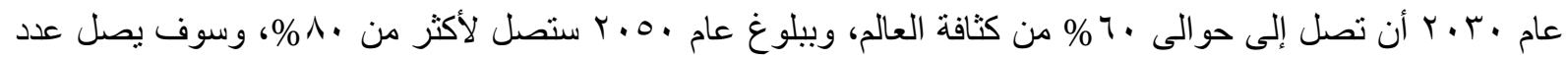

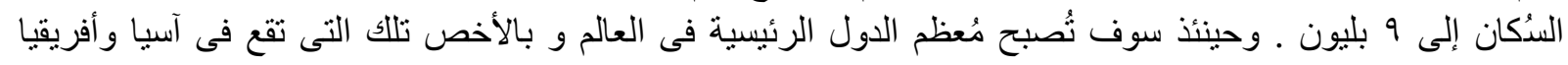

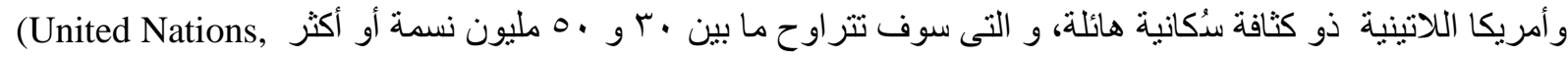

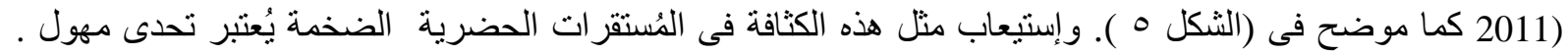

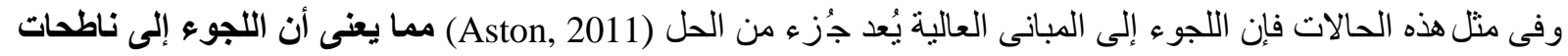

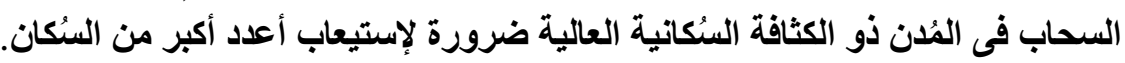

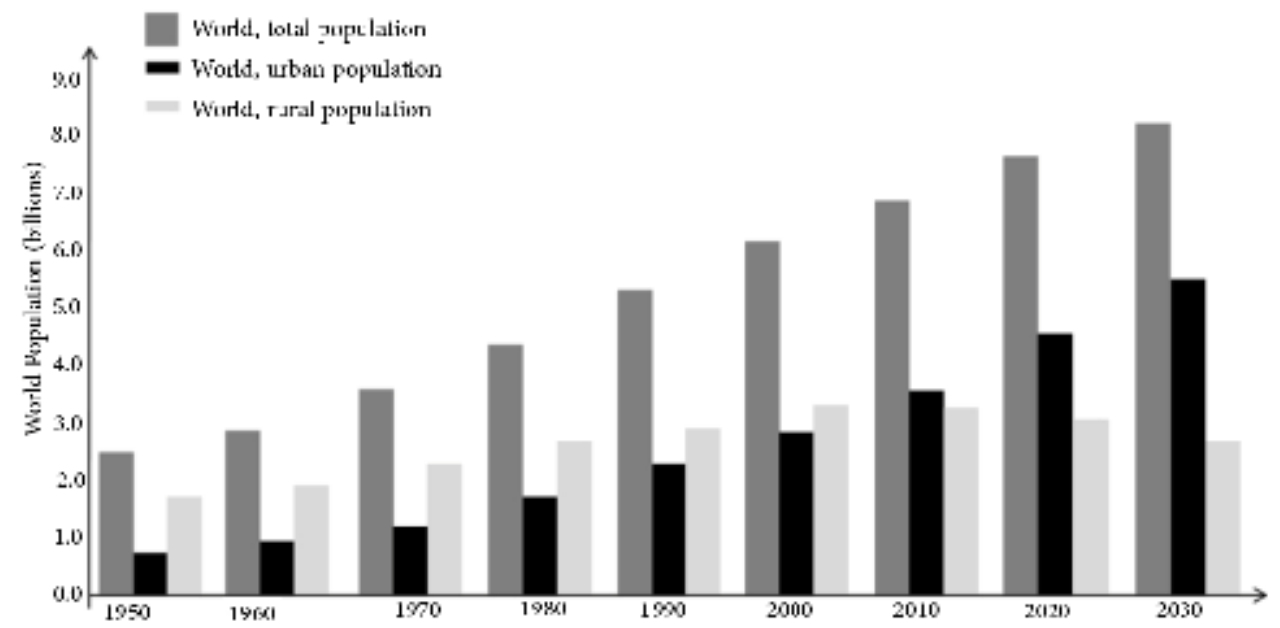

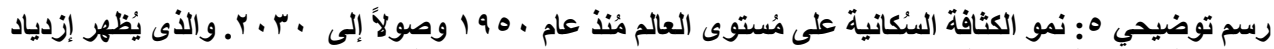

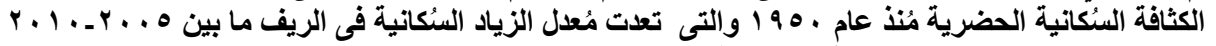

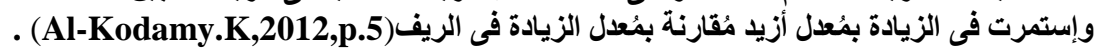

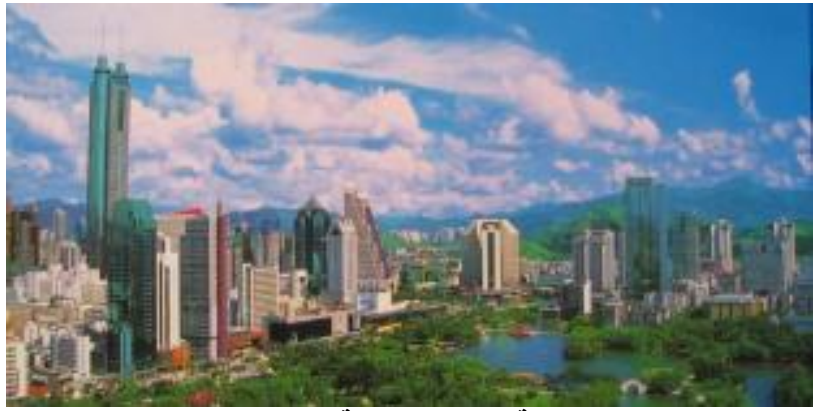

رسم توضيحي 1": مدينة شينزن الصينية Shenzhen بعد تحولها إلى (McKen مدينة صناعية (McKenzie, 2014).

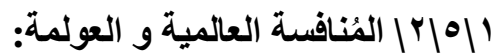

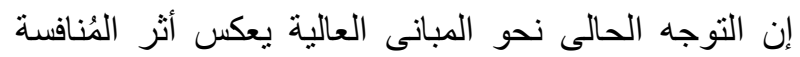

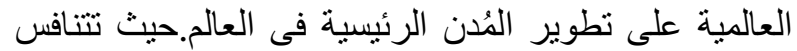

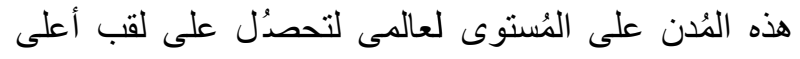

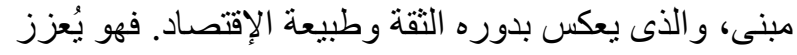

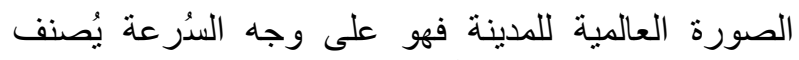

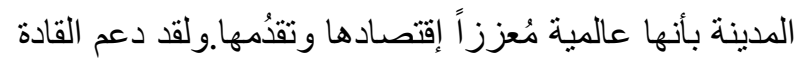

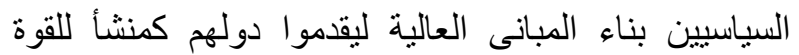

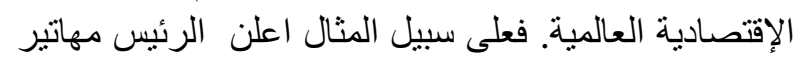

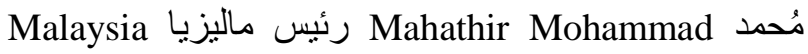

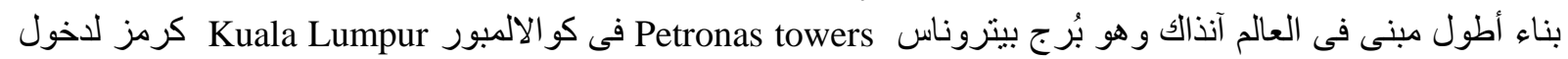

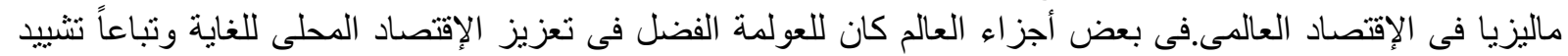

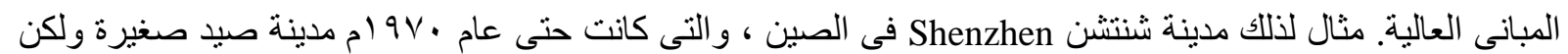

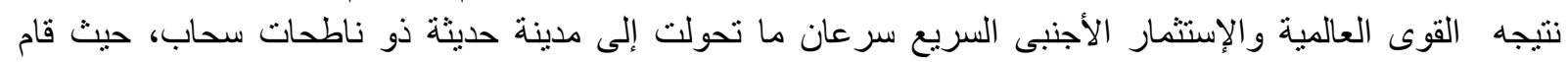

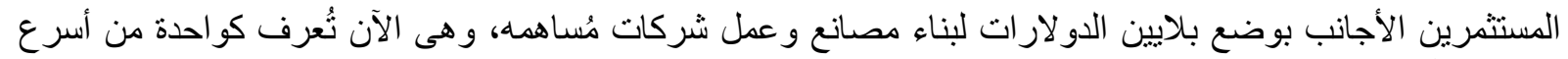

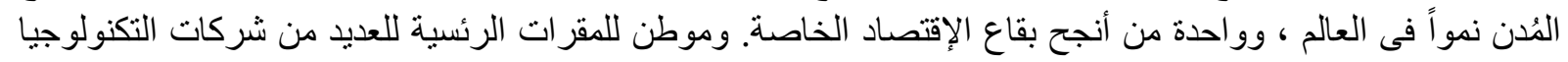

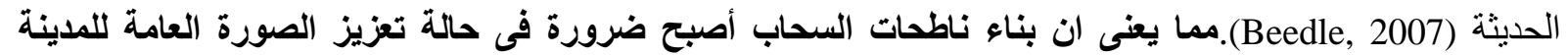
وإظهار إستقرار ها الإقتصادى.

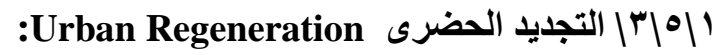

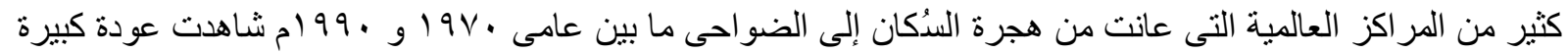

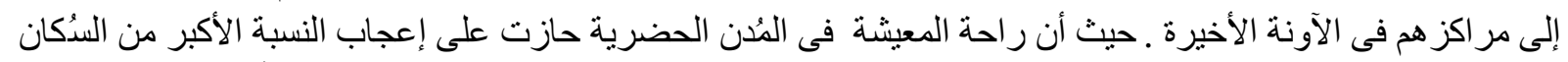

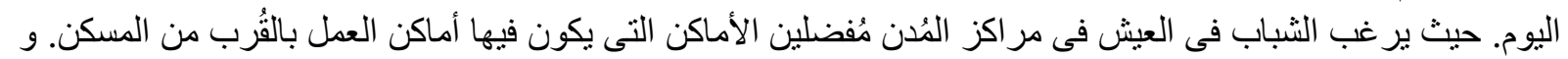




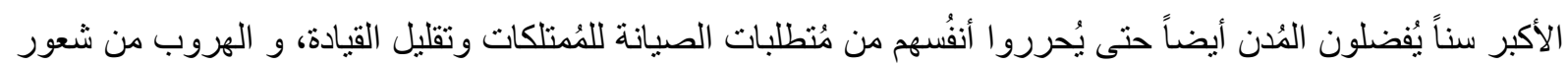

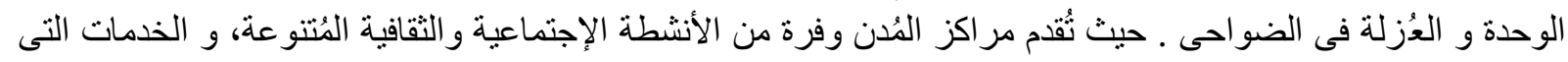

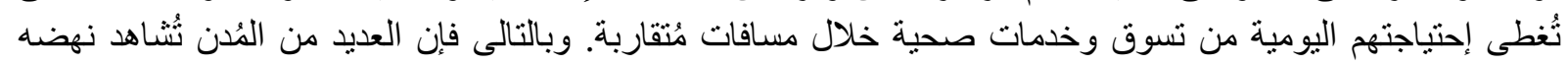

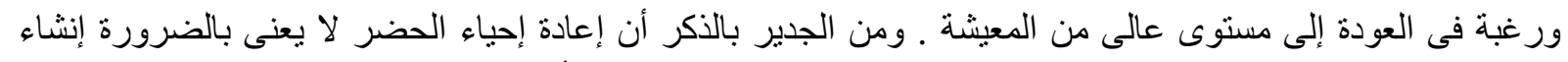

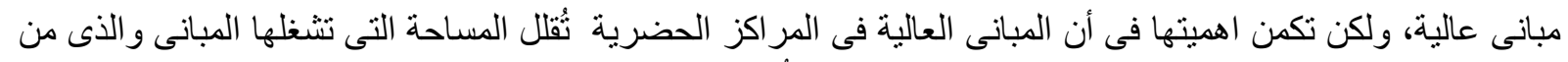

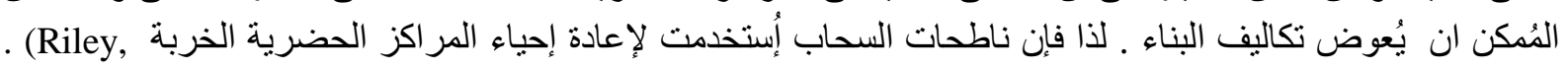

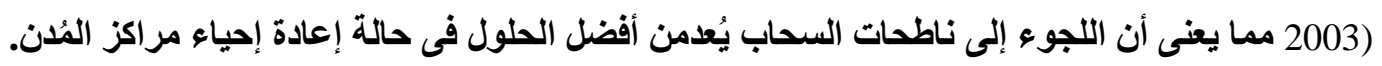

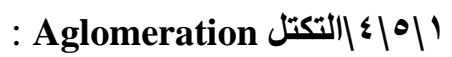

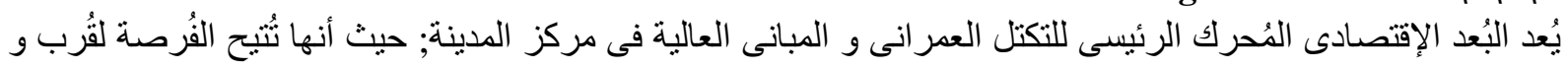

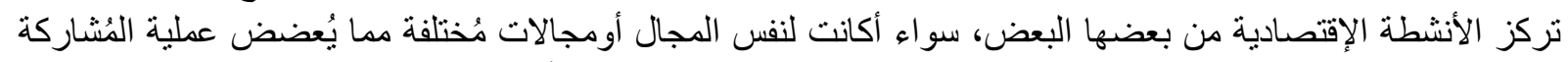

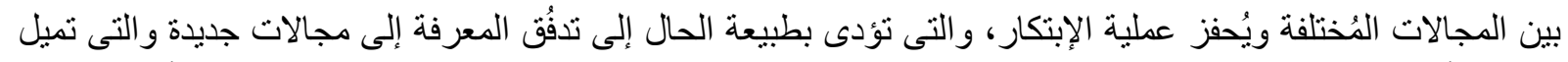

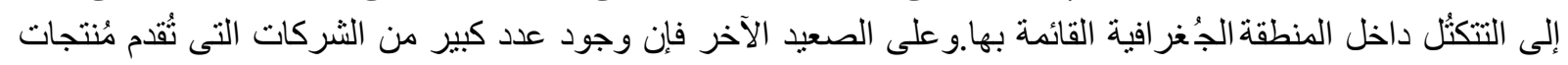

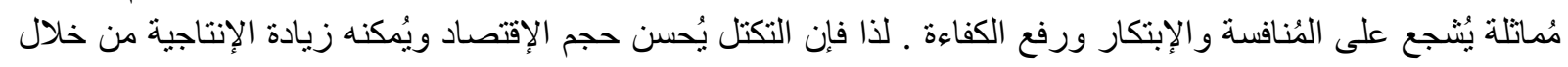

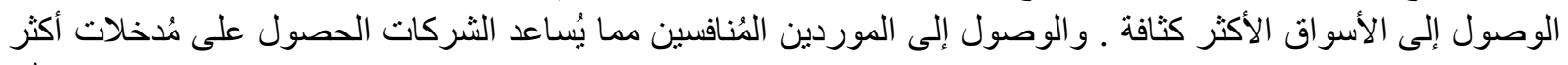

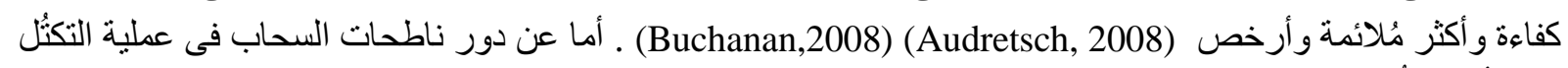

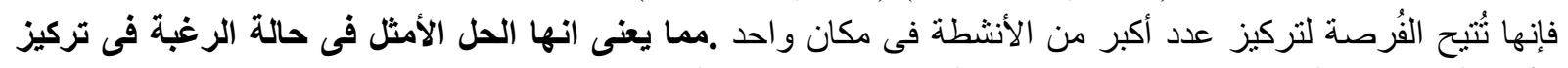

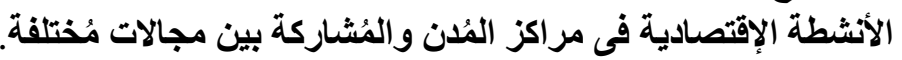

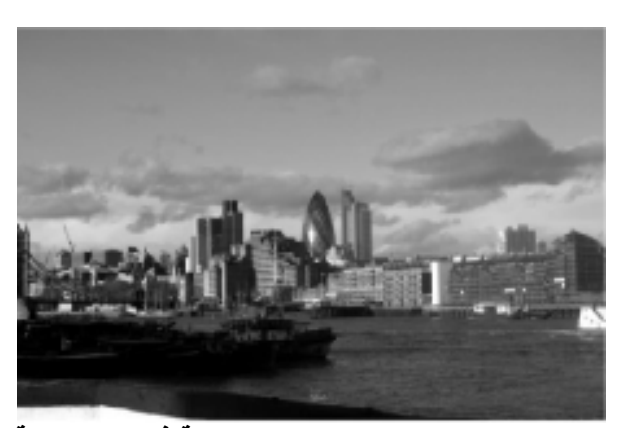

رسم توضيحي V: إنشاء المبانى العالية فى لندن نتيجة

إرتفاع أسعار الأراضى Al-) K.AL-Kodamy

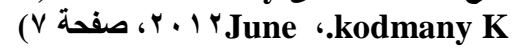

1أل101أسعار الأراضي: لقد كانت اسعار الأراضيى العامل الأولى للتوجه إلى المبانى العالية.كما حُدد

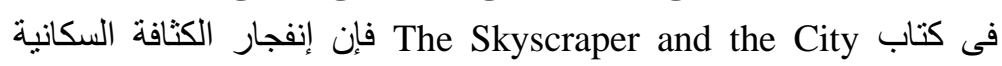

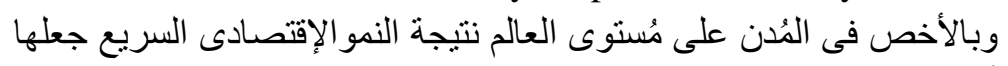

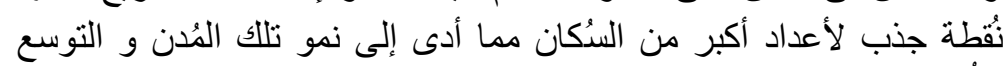

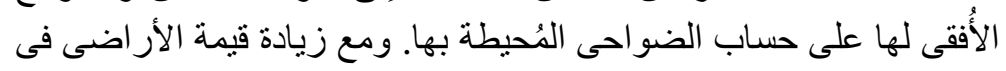

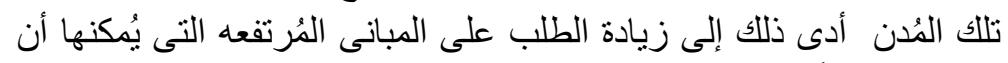

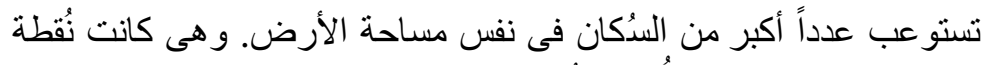

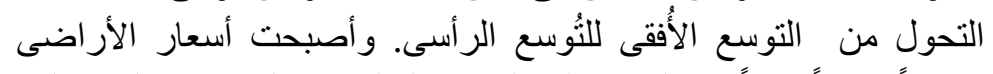

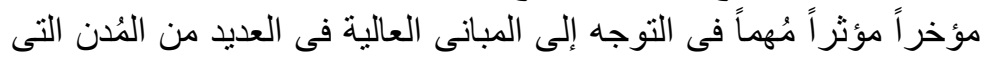

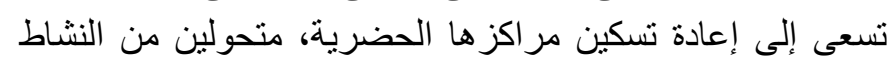

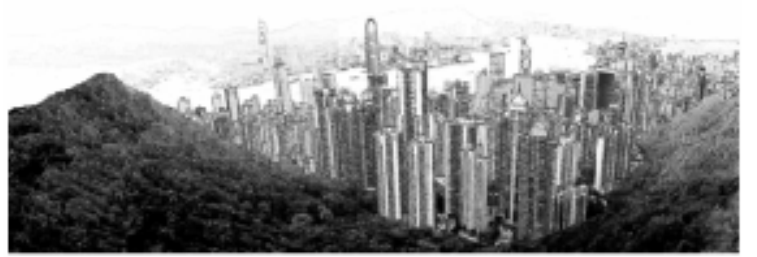

رسم توضيحي ^^ ضيق المساحة القابلة للبناء فى هونج كونج نتيجة

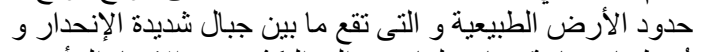

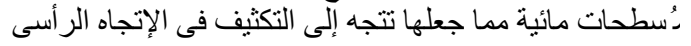

(Al-kodmany K. , June 2012)

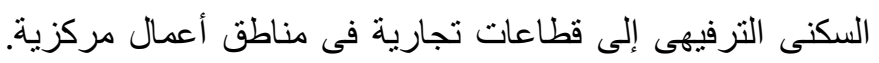

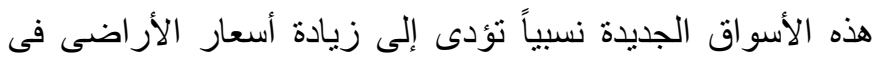

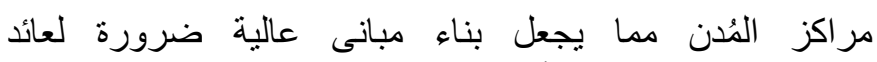

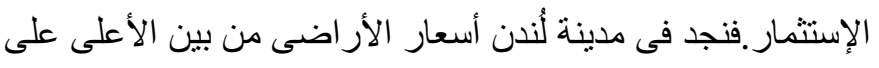

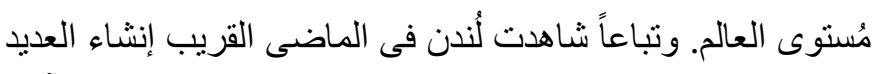

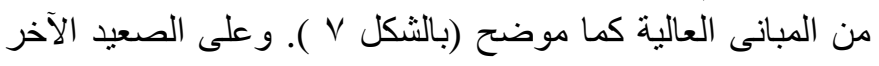

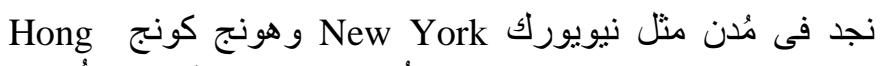

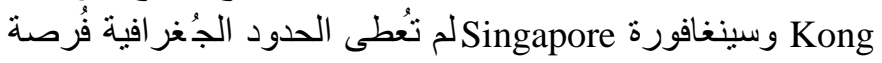

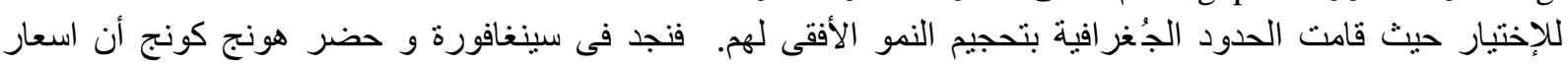

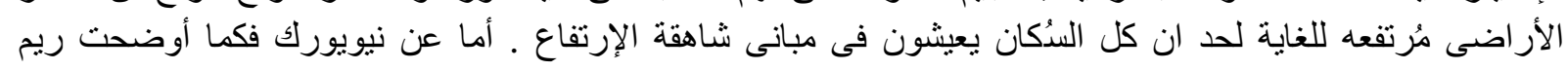

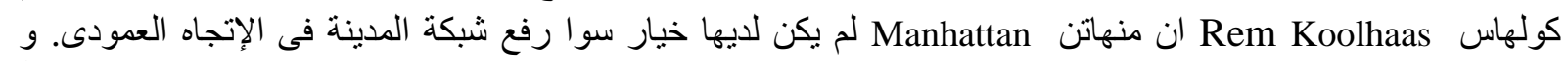

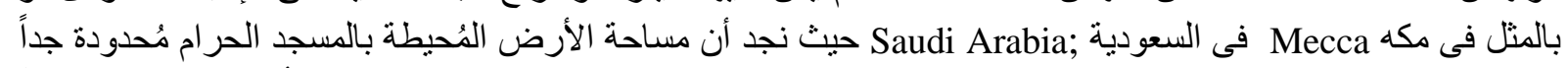

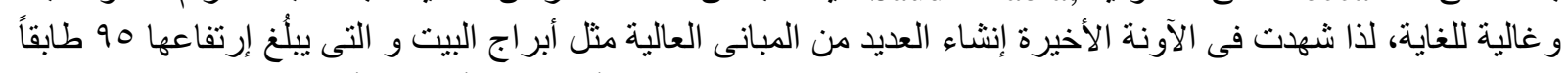

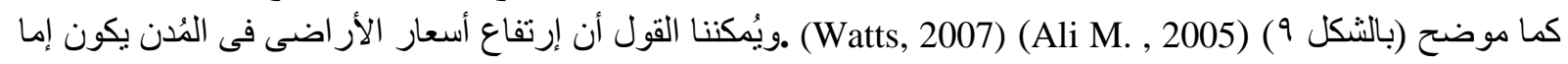




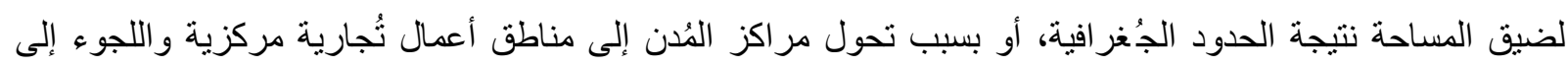

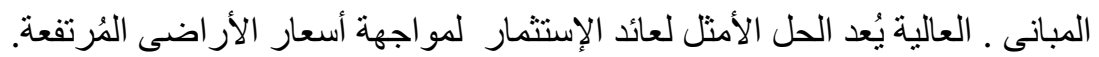

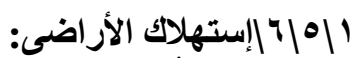

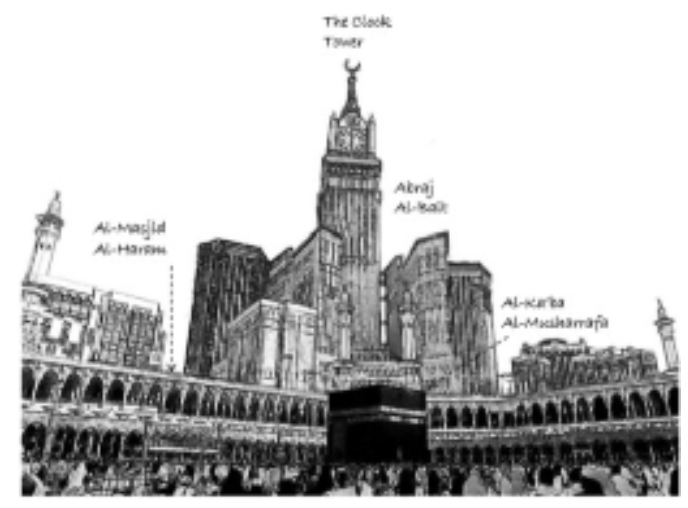

رسم توضيحي 9: أبراج البيت فى مكة المئكرمة فى

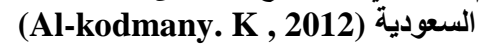

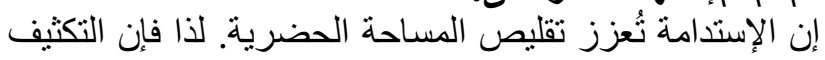

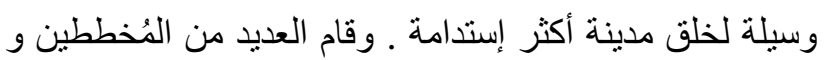

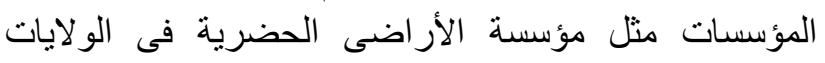

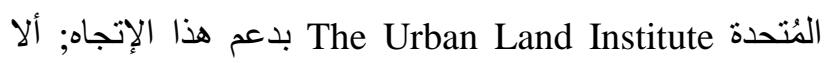
وهو أنه من خلال الزيادة الإستراتيجية لعدد الوحدات السكنية الإنية

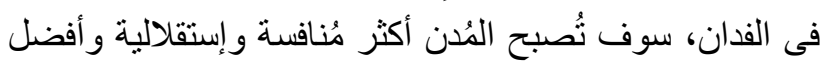

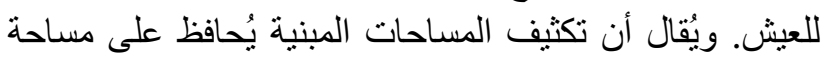

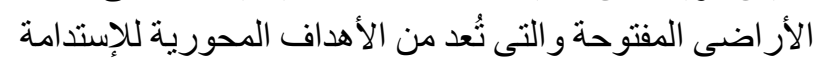

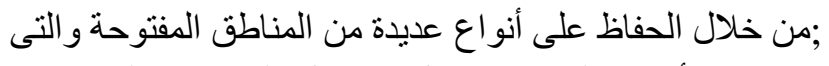

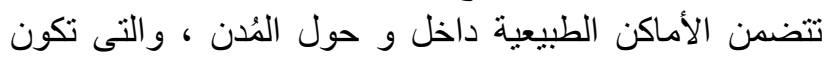

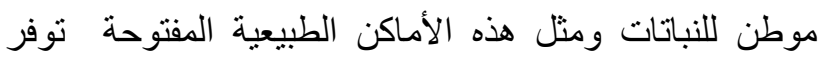

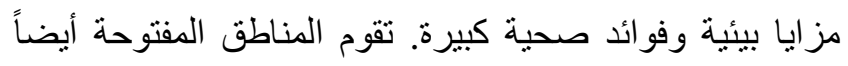

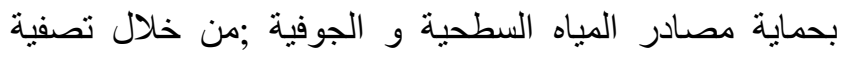
النفايات و الحطام و الملوثات الكيميائية قبل دخولها في نظام المياه، والتى تكون في كثئ كثير من الأحيان أقل تكلفة بالنسبة

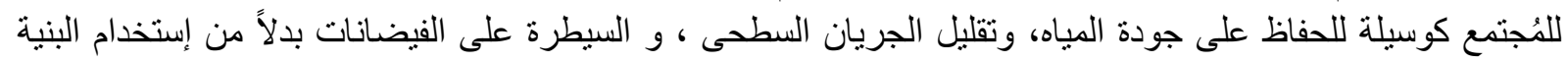

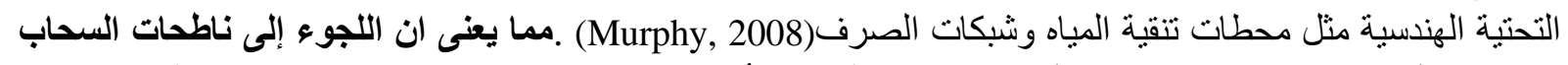

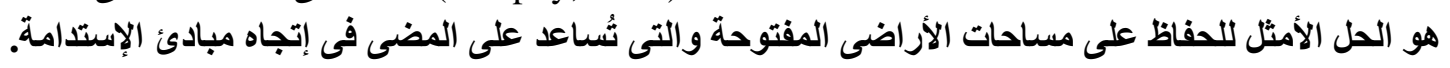

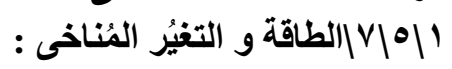

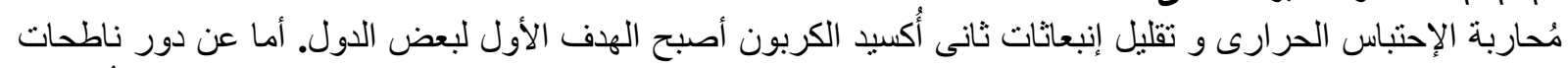

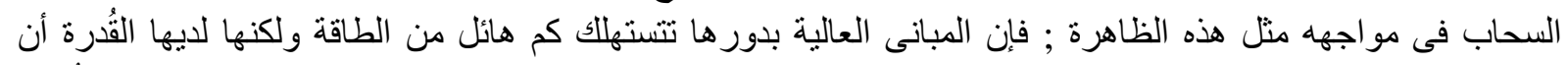

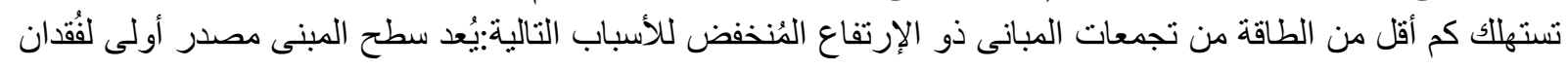

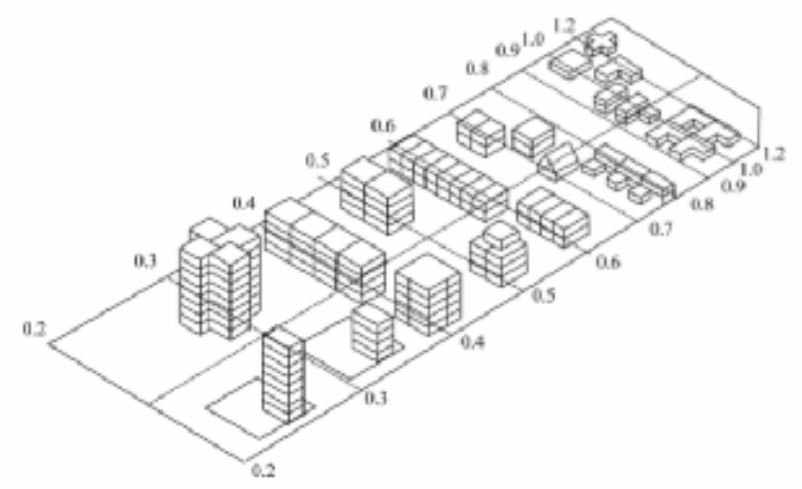

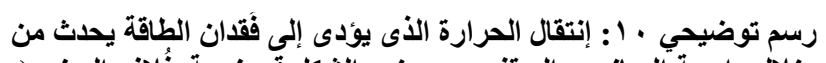

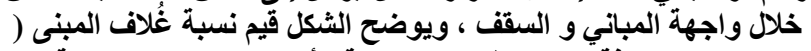

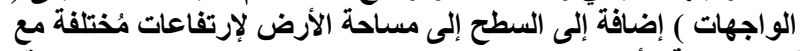

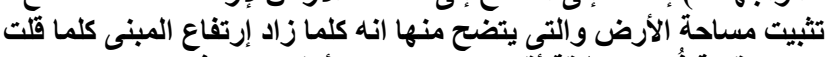

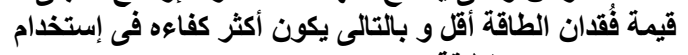

(Aldeberky, p. 9) الطاقلى

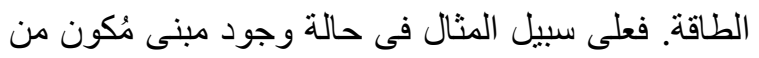

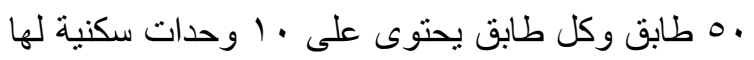
سطح واحد،

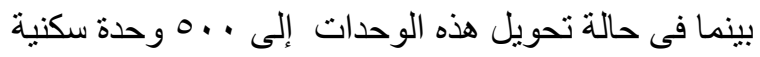

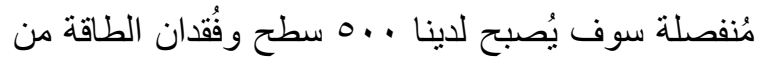

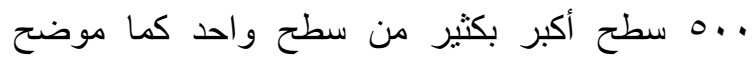
(بالثكل · (1). إضافة إلى ذلك فئر فإن المبانى العالية يمكن

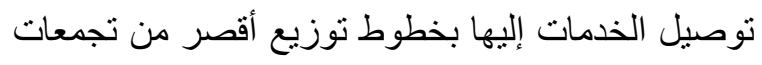

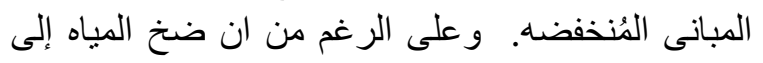

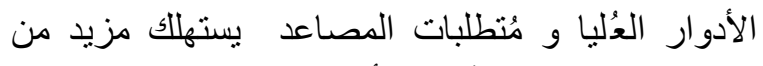

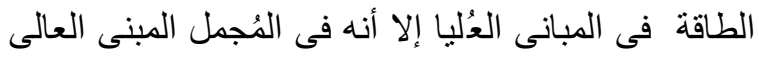

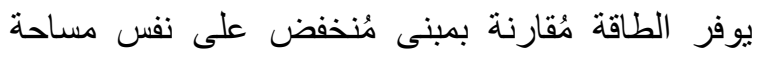
الأرض و هو الر أى الذى دعمه فوستر (Foster, Foster) (Dalton, 2008, p. 102 112) اللجوء إلى ناطحات السحاب يُعد الحل الأمثل لتقليل إنبعاث ثانى أُكسيد الكربون. 


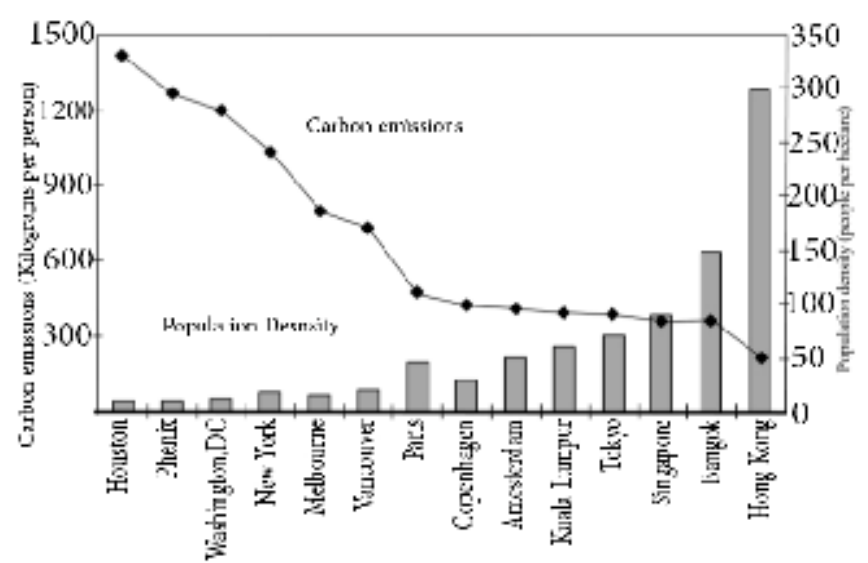

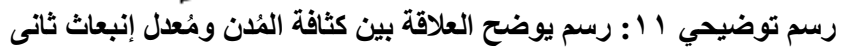

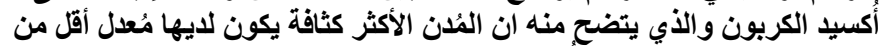

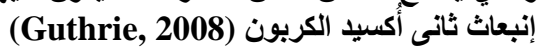

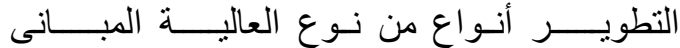

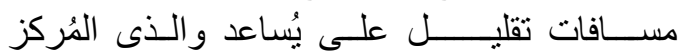

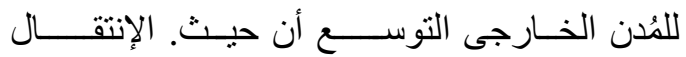

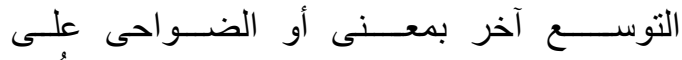

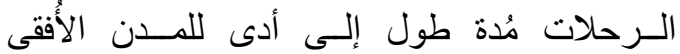

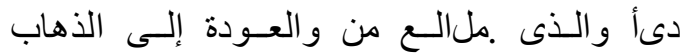

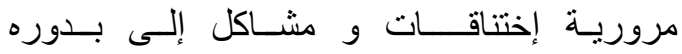

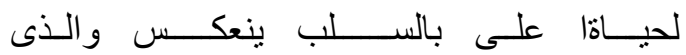

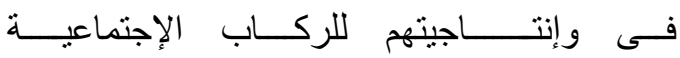

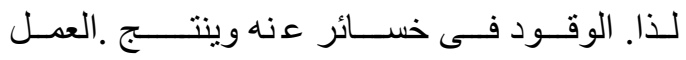

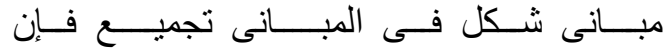

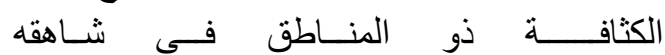

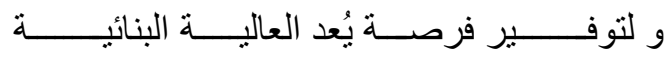

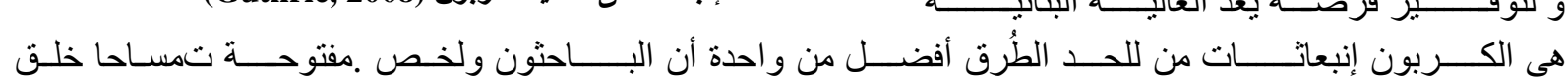

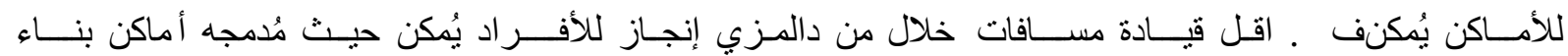

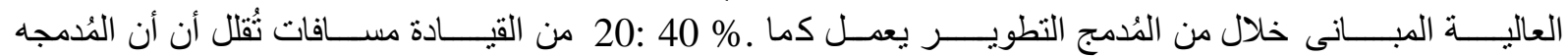

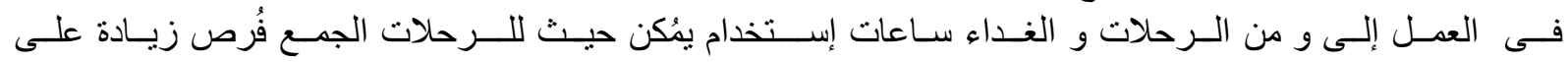

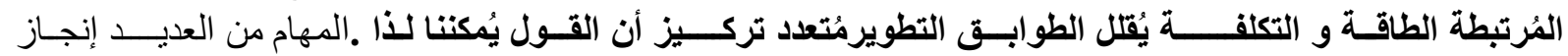

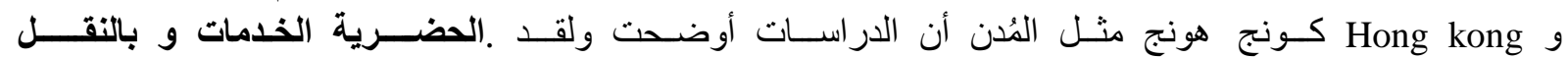

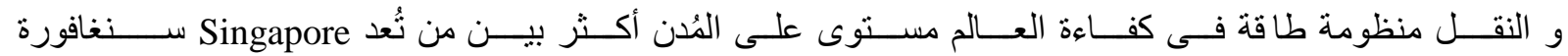

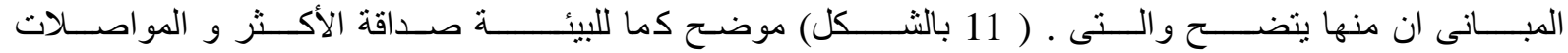

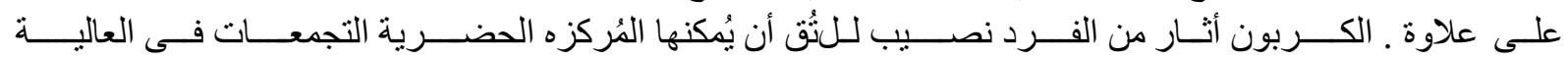

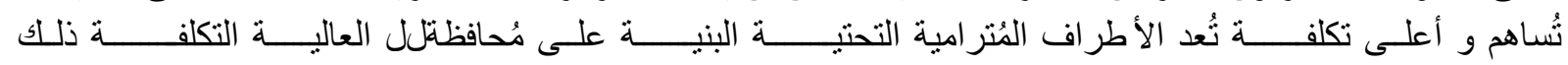

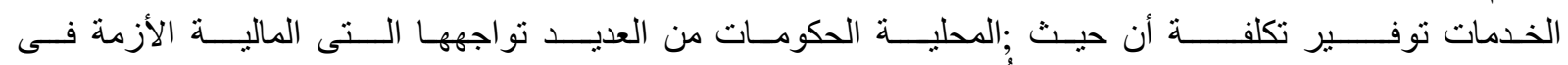

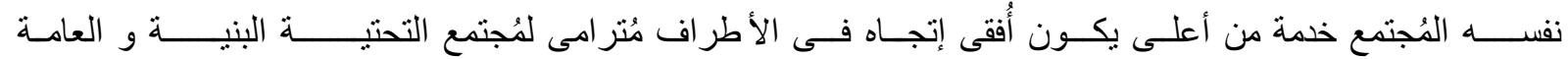

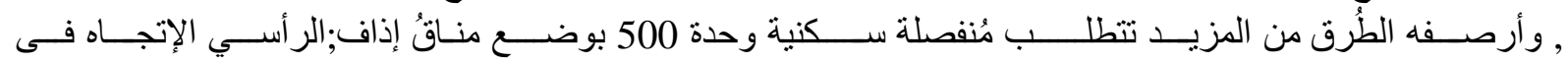

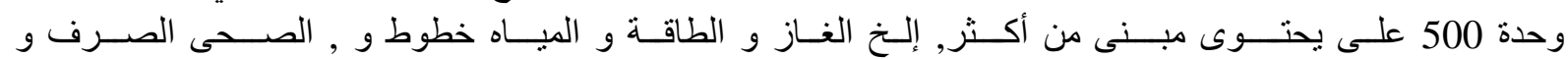

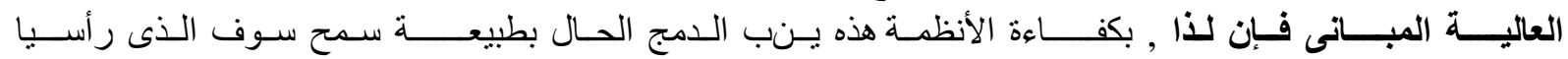
(Ali, 2010) (LS Beedle M. M., 2007) (Ewing, 2008)

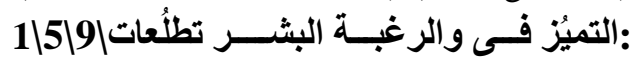
psycho

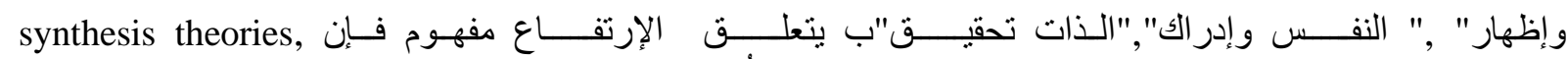

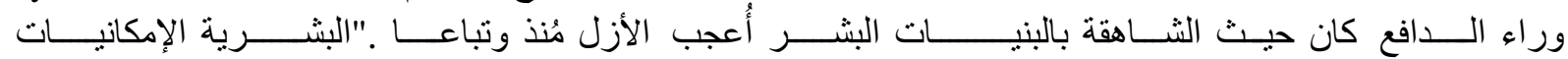

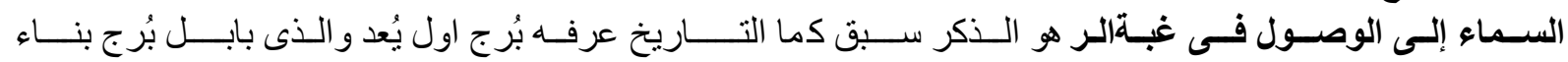

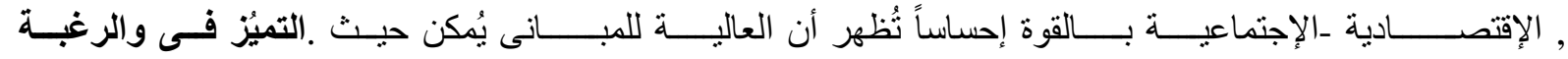

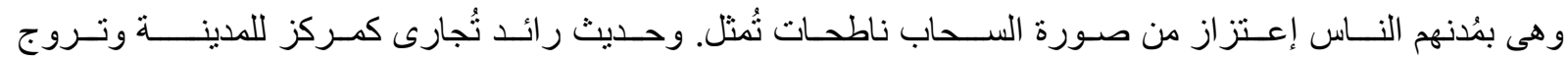

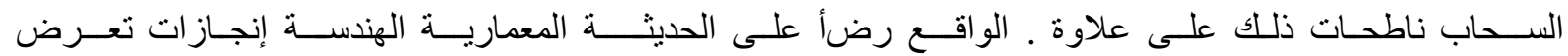

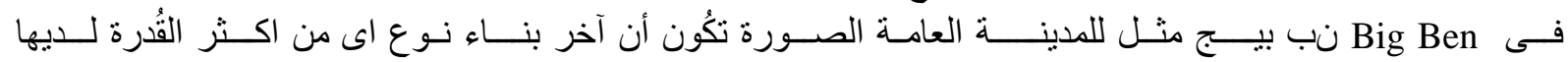

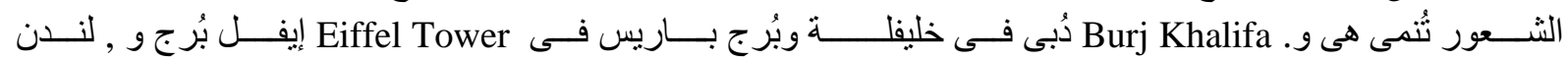

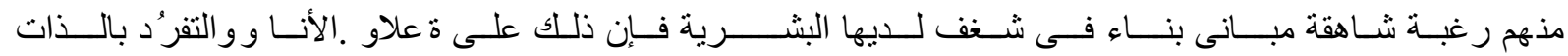

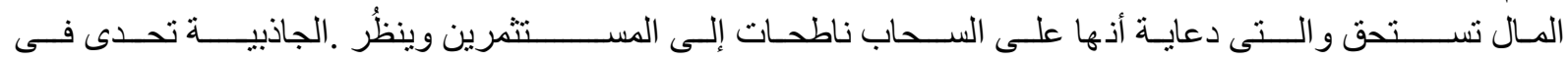

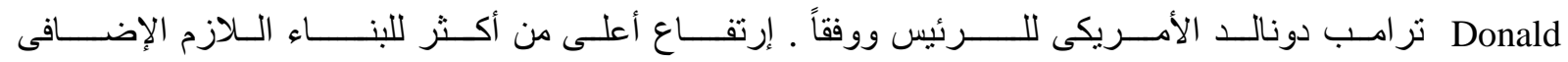




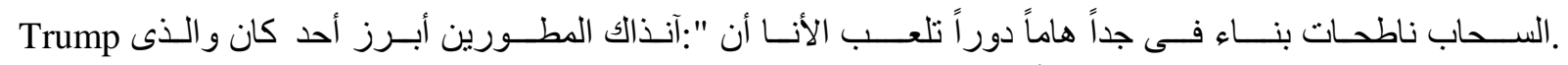

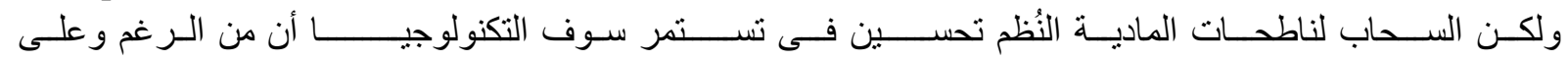

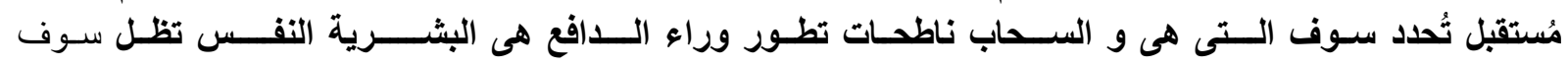

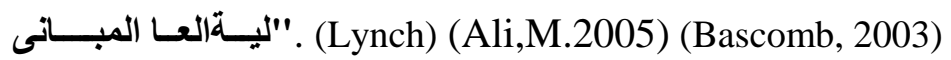

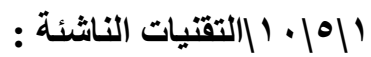

حيث أصبحت تكنولوجيا العصر مُنطورة على نحو مُتنز ايد مما فتح الباب للمعماريين فى بناء مبانى بالغة الإرتفاع ومُمارسة

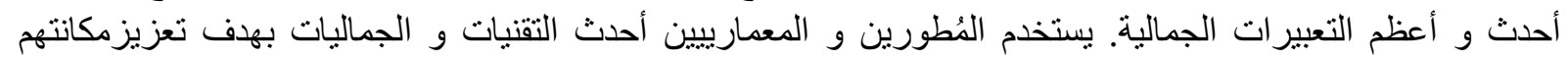

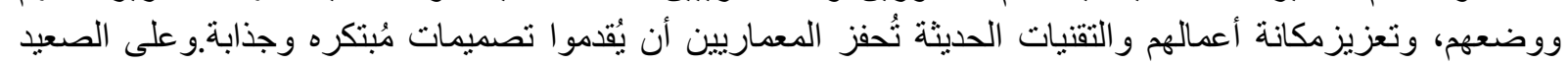

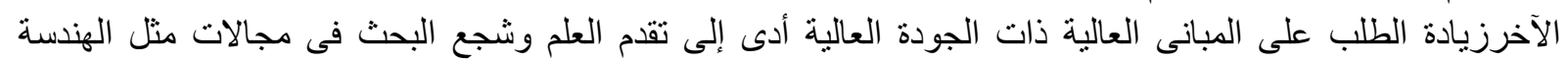

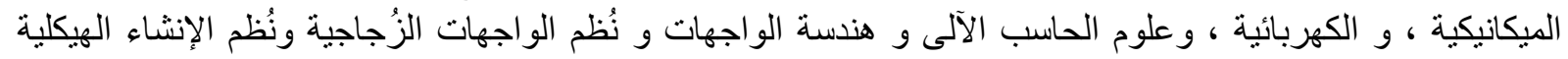

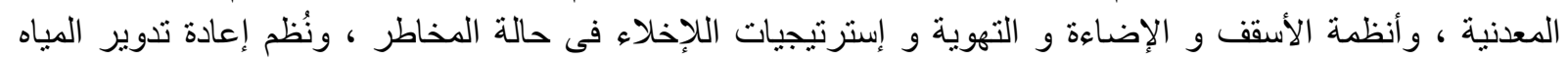

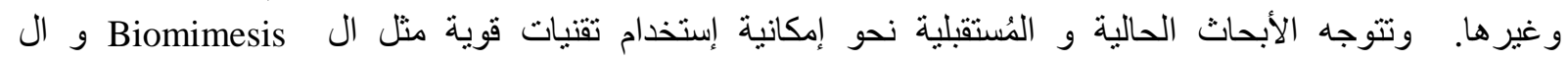

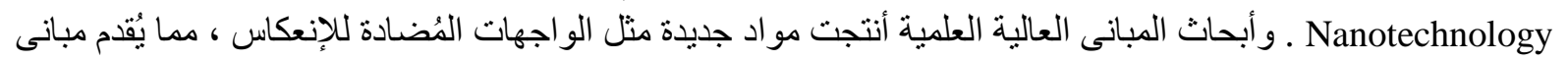

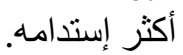

(Al-kodmany, K. 2012) (Wood, 2011)

الآالجدل ضد ناطحات السحاب ، المساوئ و التحديات:

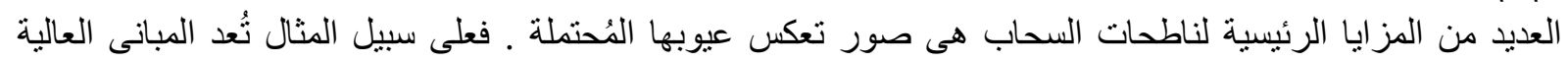

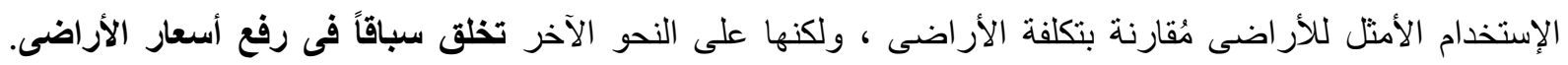

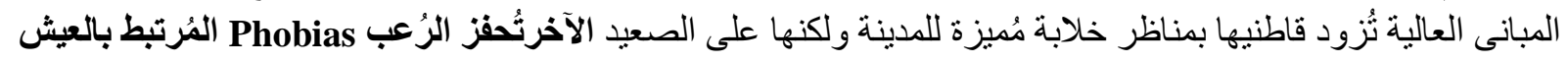

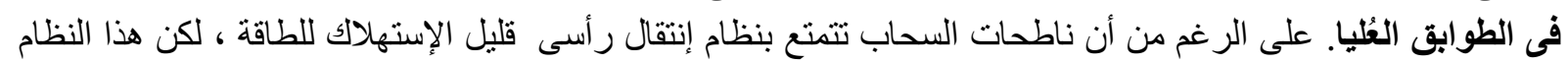

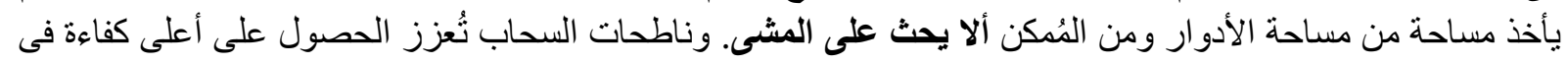

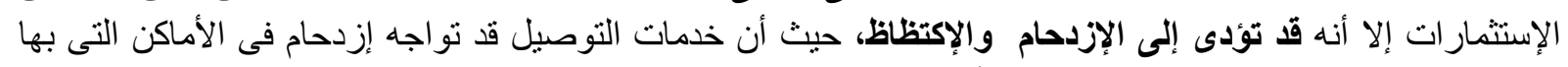

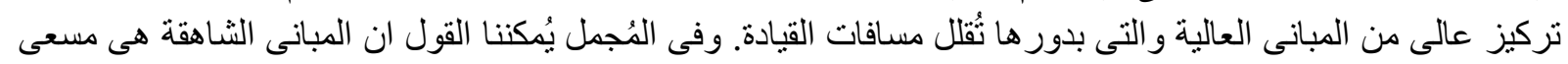

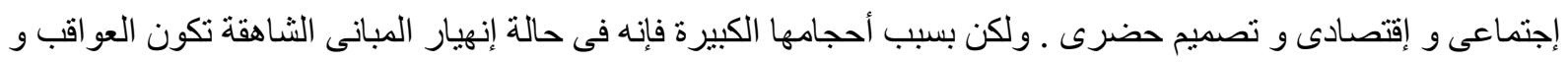

الخسائر هائلة. (Owen, 2009)

الآ|الإلإتتصاد:

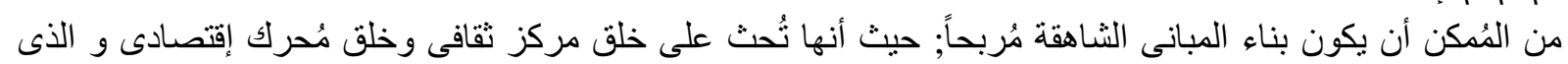

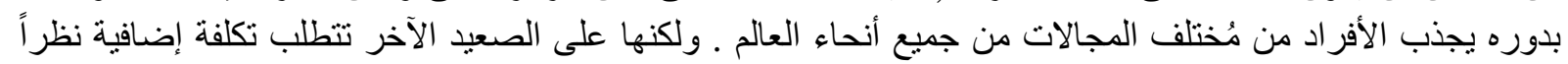

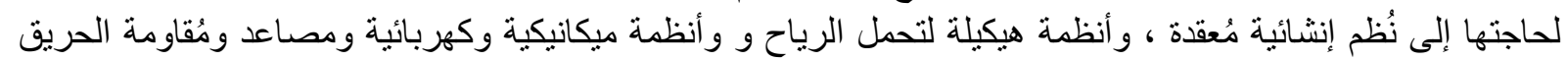

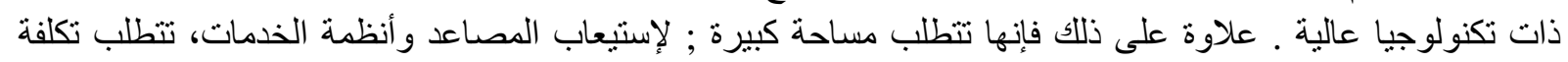

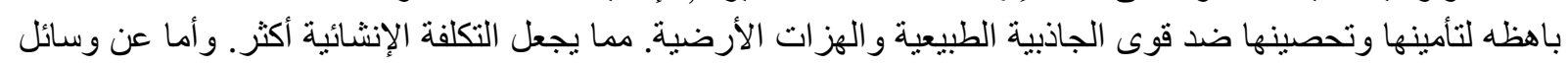

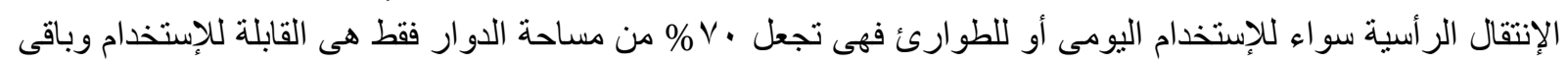

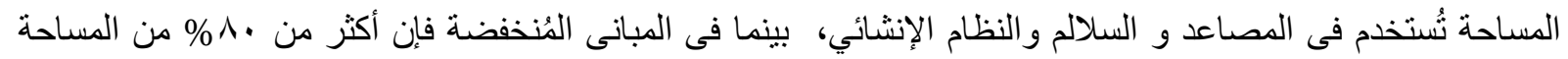

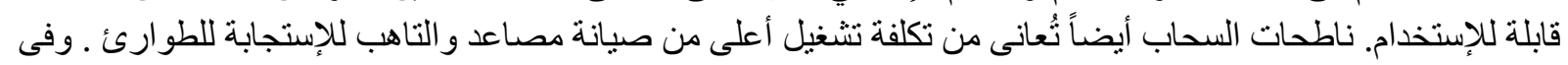

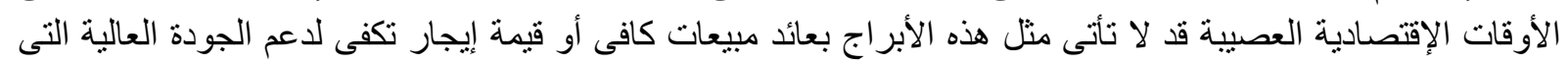

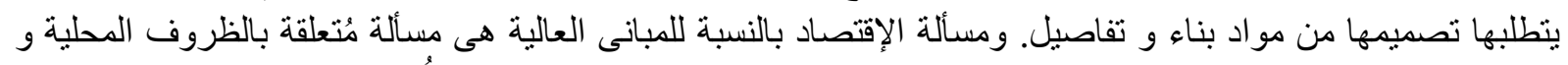

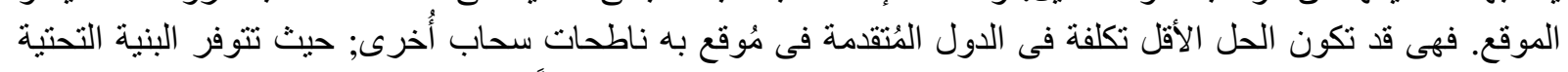

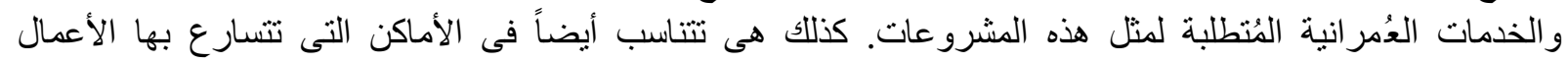

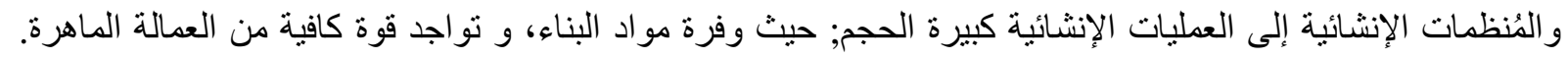

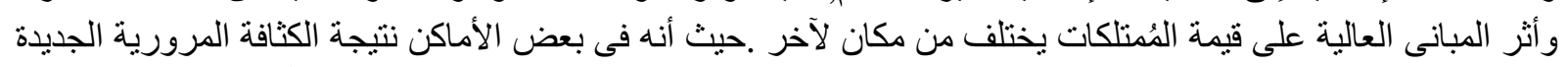

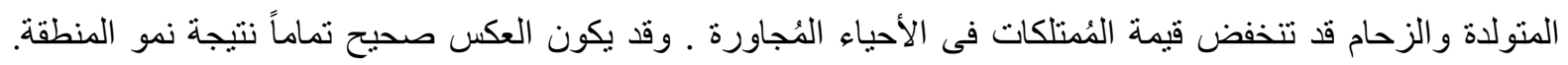

(Yeang, 2008, p. 84 94) 


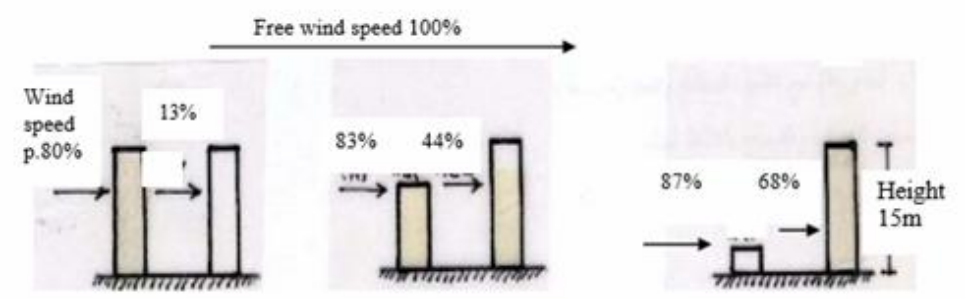

رسم توضيحي ب ا : نسبة سُرعة الرياح فى الأماكن المفتوحة خلال المبانى (Aإنى

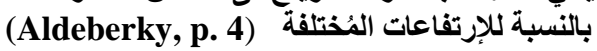

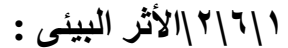

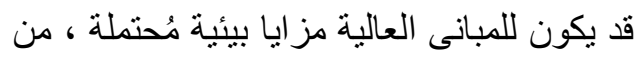

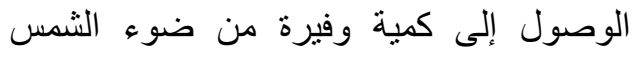

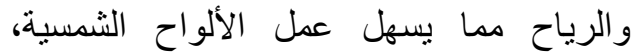

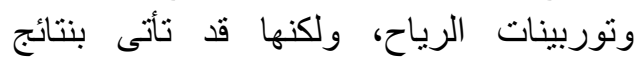
مُعاكسة على النطاق الأرحب.ومن ضمن ضكن الآثار

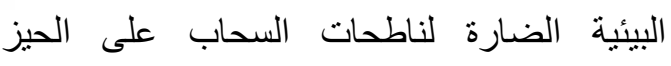

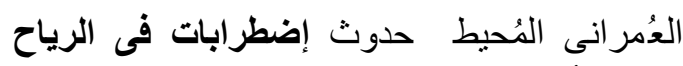

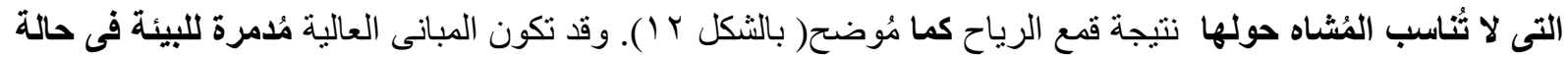

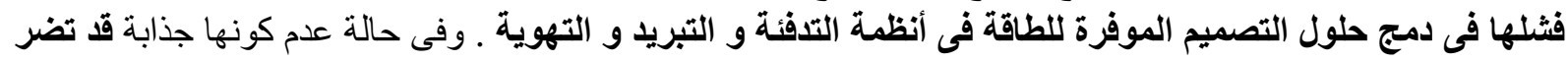
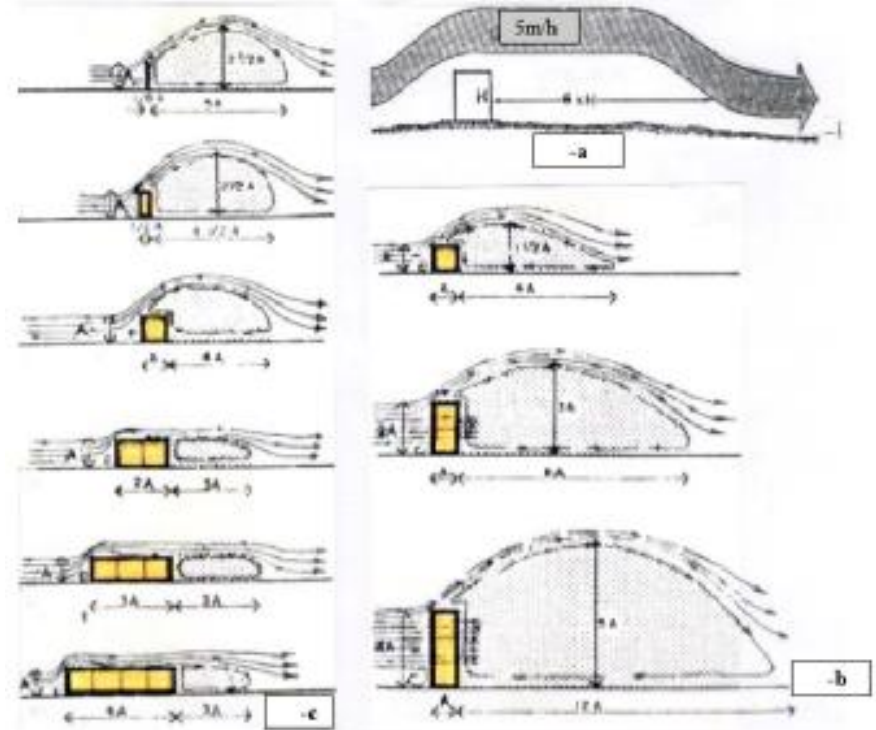

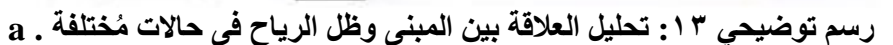

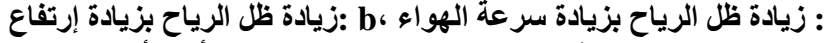

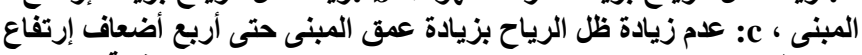

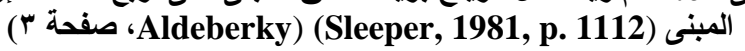

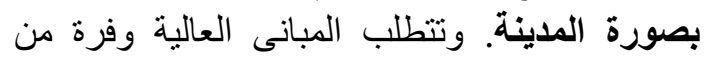

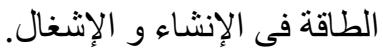

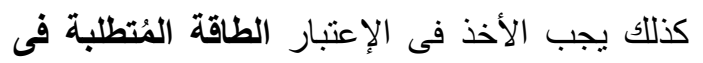

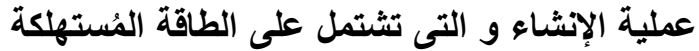

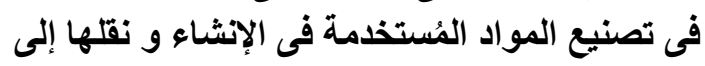

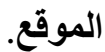
وبناء على العديد من الدراسات البيئية حول الثنأثير البيئى لناطحات السحاب يُكنتنا تلخيص الأثر البيئي

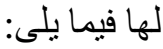
ـتؤُث ناطحات السحاب على الرياح فى الحيز

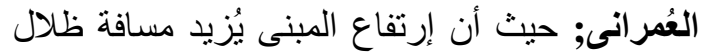

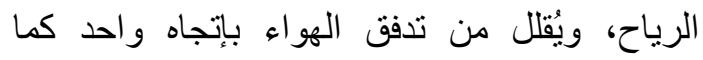

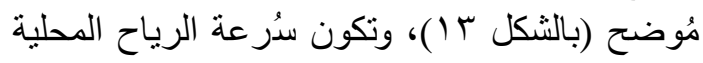

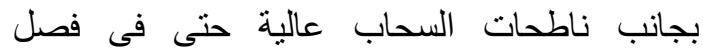

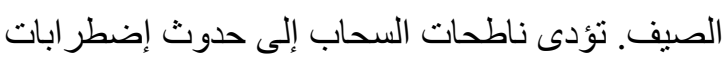
عنيفة في تدفق الرياح التدريجي كما موضح.

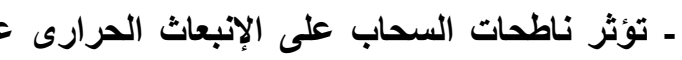

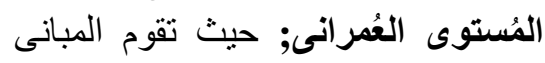
العالية بإمتصاص أنشعة الثمس المُباثنره

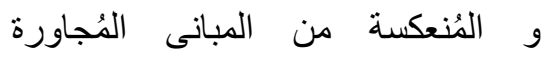

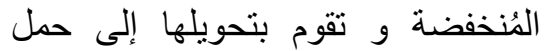
حرارى ذو موجات إنعاعية طويلة والتى بطبيعة الحال يتم تخزينها داخل

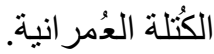

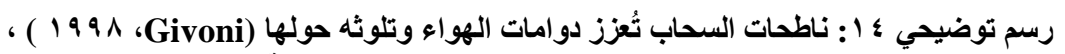
وتحجب الرياح وتعكس الإثعاع الثمسى على المبانى المُنخفضة (ئنس

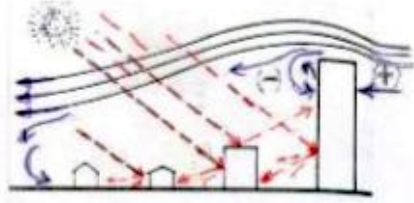

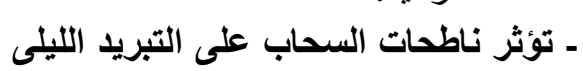

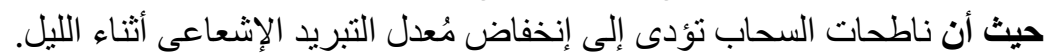

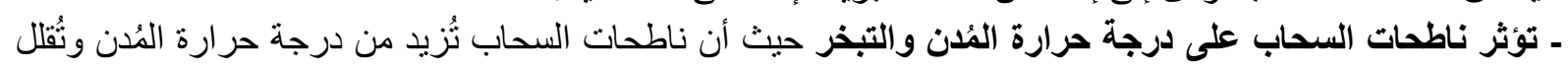

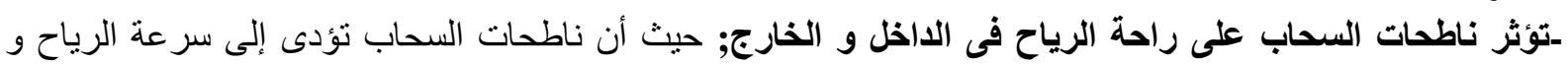

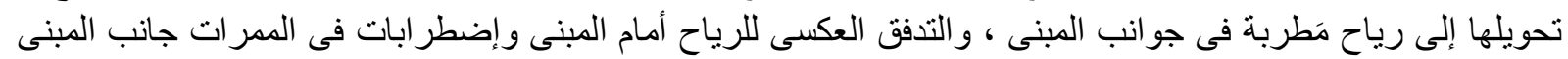

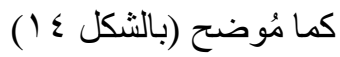
- يتؤثر ناطحات السحاب على مثلوثات الهواء حيث أن ناطحات السحاب ثُعزز ملوثات الهواء. 
(Aldeberky) (Merghani, 2002, p. 725) (Fader, 2008) الآآالبنية التحتية: المبانى العالية توفر العديد من المز ايا من إثغال الأرض بكائه بكفاءه عالية، وتقليل مسافات رحلات العمل اليومية. ولكنها قد نولد

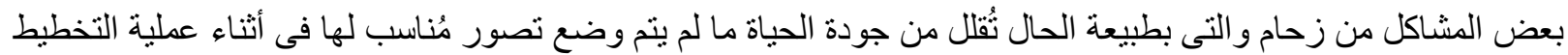

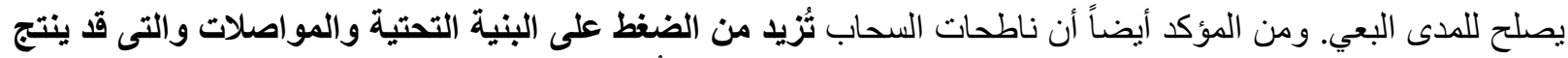

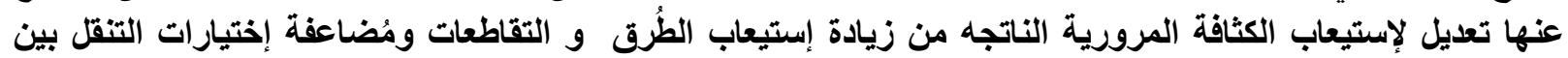

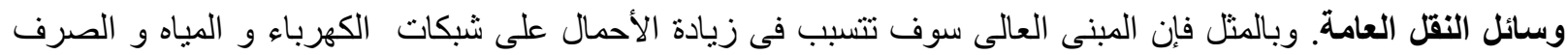
الصحى القائمة. (Ewing, 2008) (Ali, 2010) الآلإكالعوامل الثقافية و الإجتماعية:

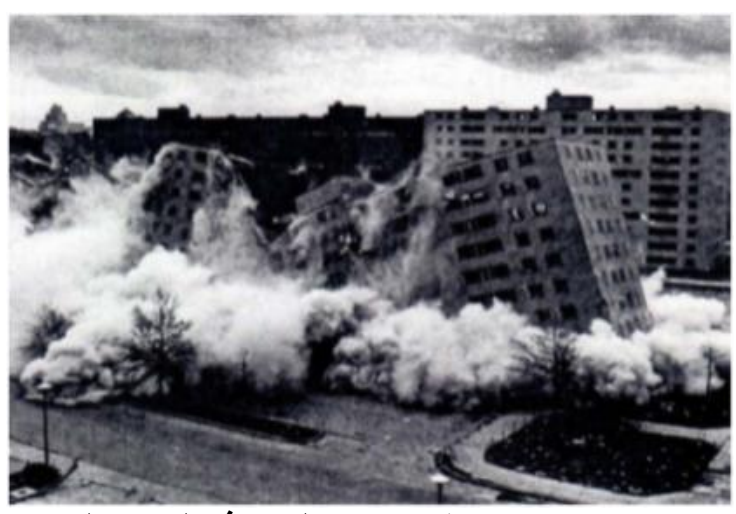

رسم توضيحي 1 ا : مشروع ساتت لويس فى الولايات المُتحدة

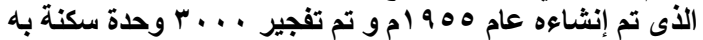

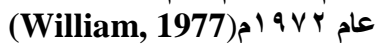

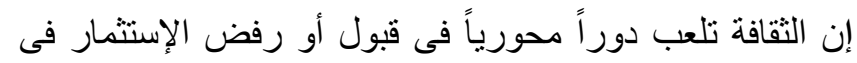

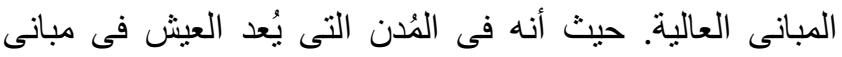

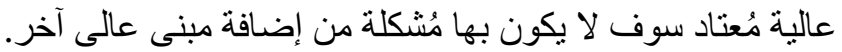

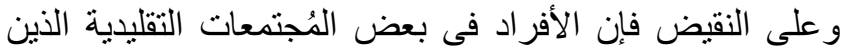

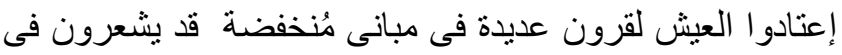
بادئ الأمر بعدم الإرنياح للعيش في مبانى عالية إلى ألى أن يتأقلموا

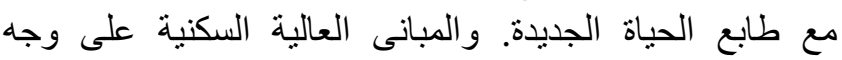

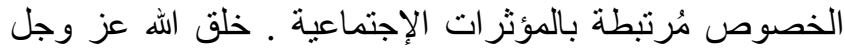
الإنسان من التراب لذا يشعر الإنسان بالإطمئنان و الإنزان الإنيان كلما

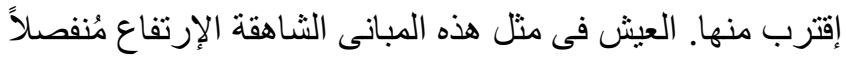

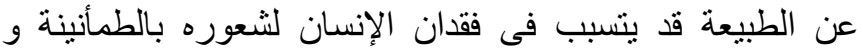

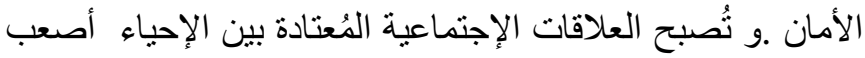

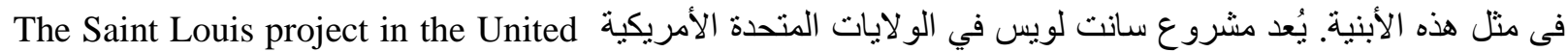

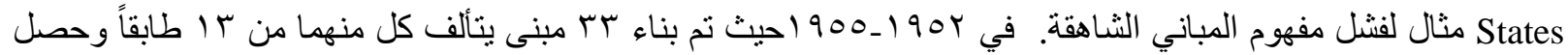

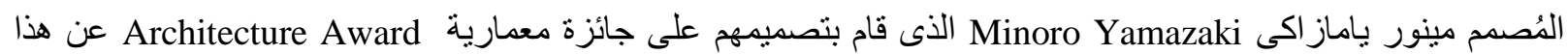

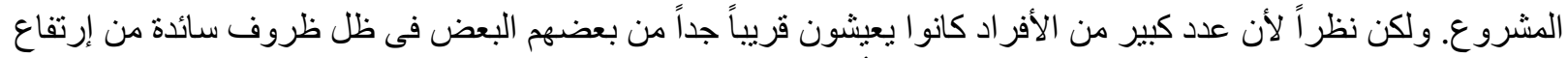

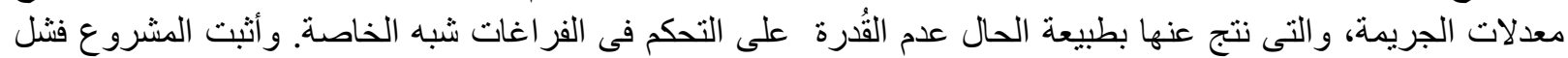

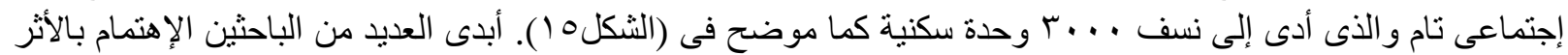

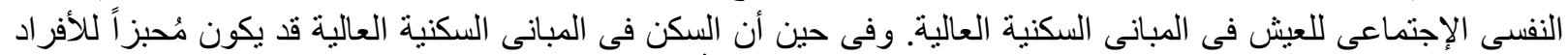

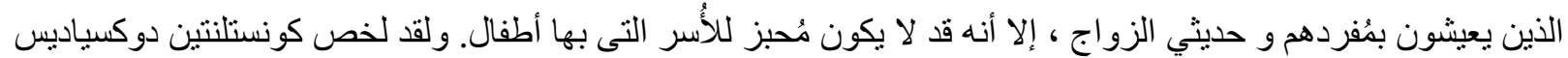

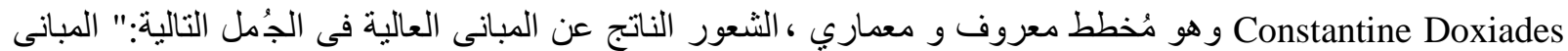

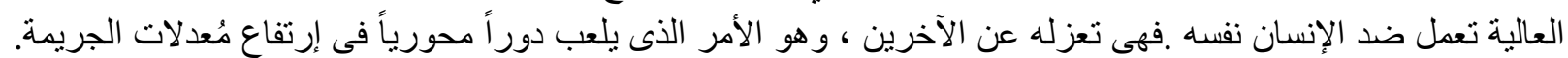

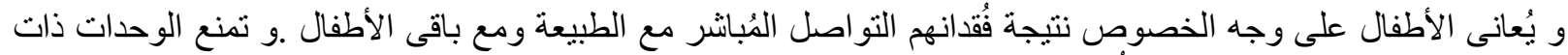

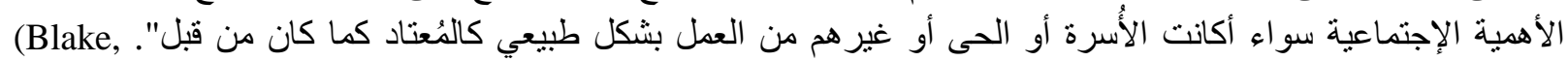

1978) (Al-kodmany K. , 2000)

| الآ|⿴囗السلامة العامة و توابعها :

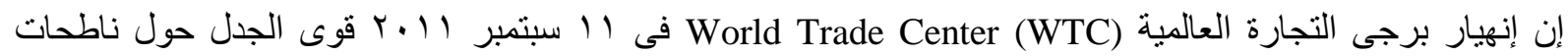

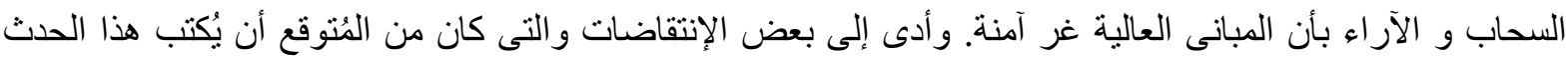

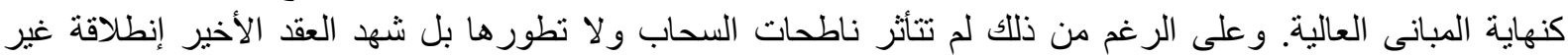

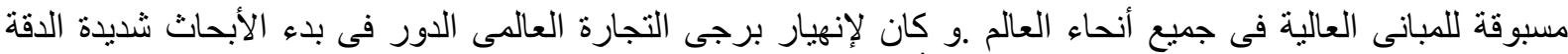

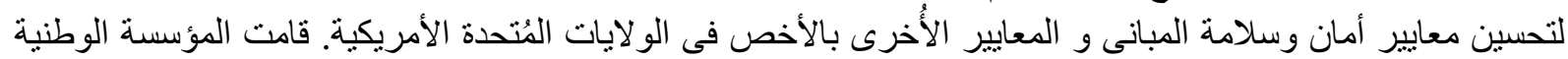

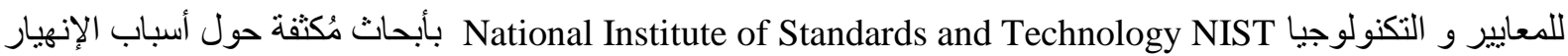

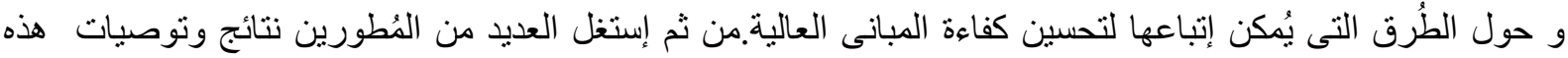
الأبحاث ووضعو ها فى الإعتبار ات التصميمية و الإنثائية (Sunder, 2004, p. 1137 1149). 
الآآتوظيفها فى السياق التاريخيى للحيز العُمرانى :

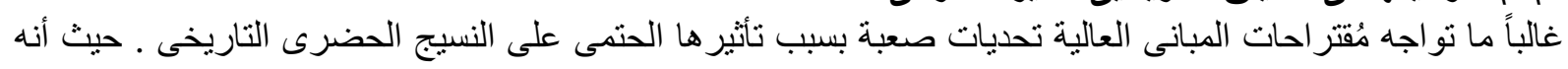

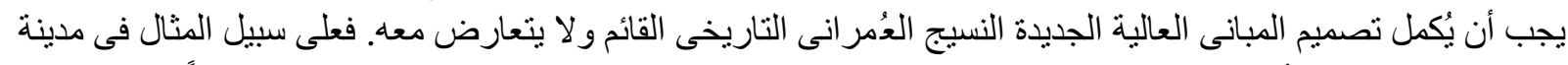

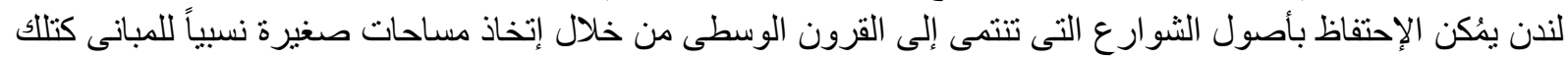

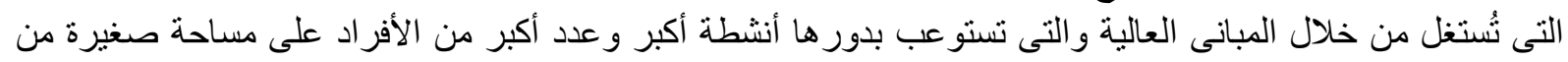

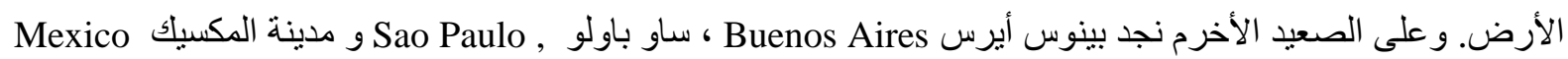

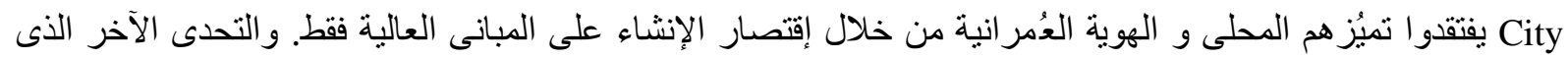

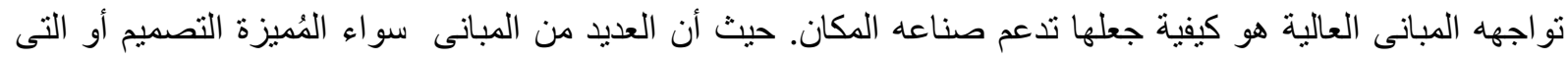

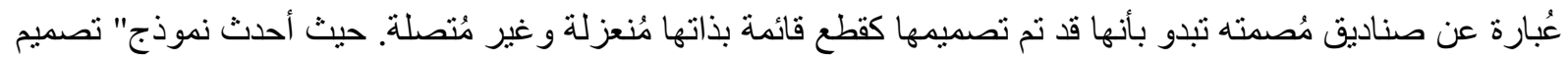

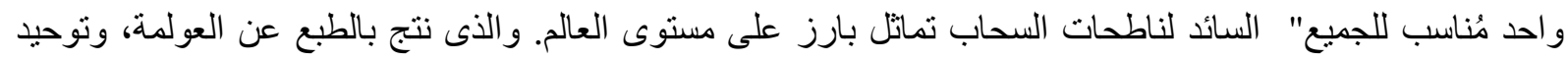

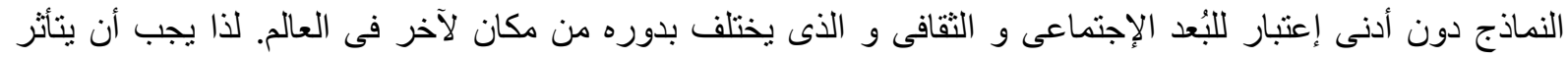

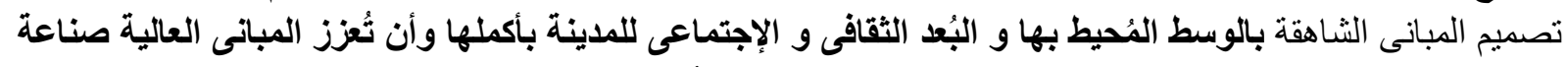

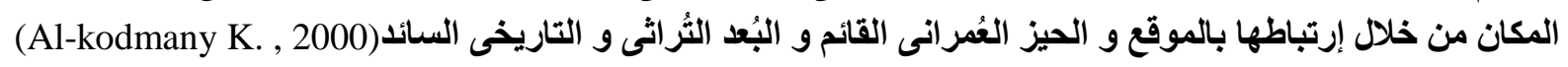

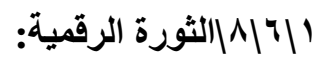

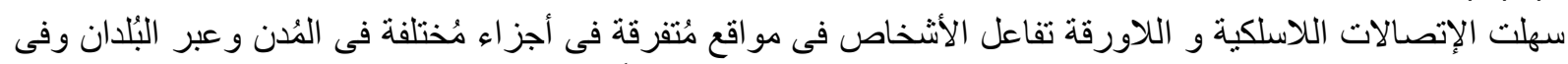

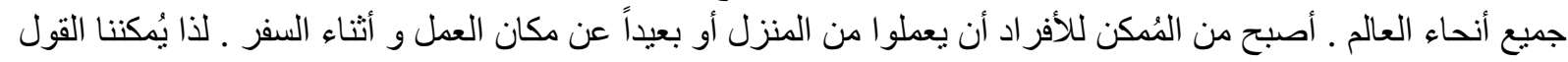

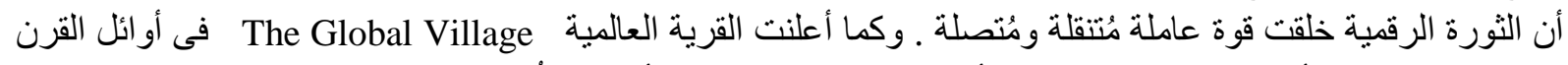

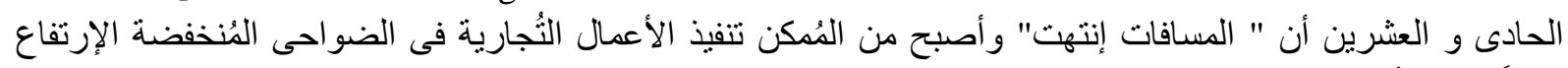

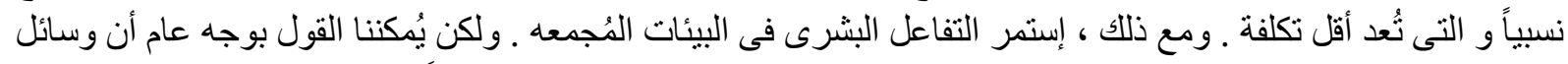

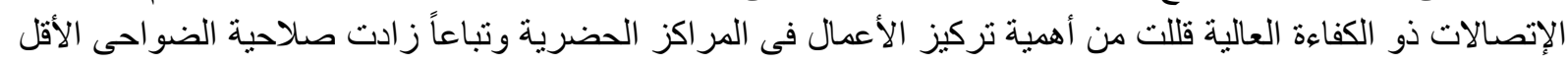

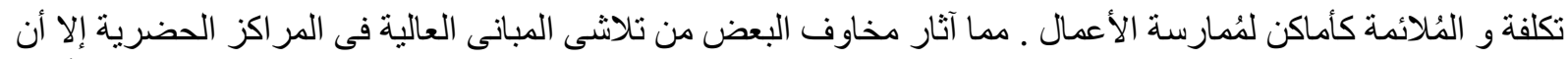

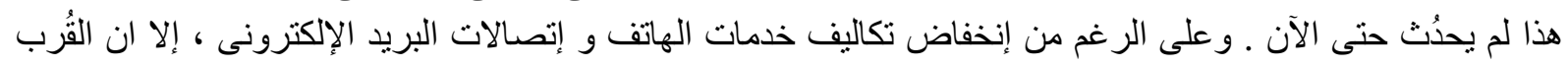
المادى لايز ال ذو أهمية (Al-kodmany K. , 2000).

\section{النتائج: خلُص البحث إلى بعض النتائج و النى تُفيد بأنه:}

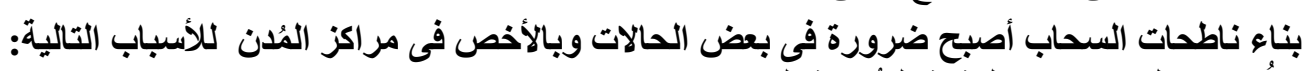

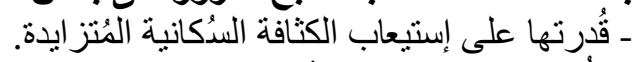

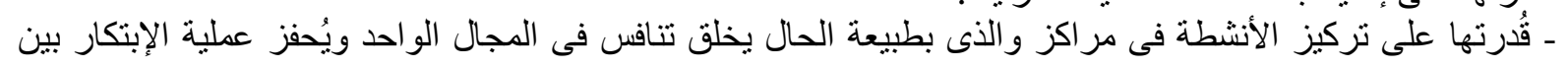

المجالات المُختلفة.

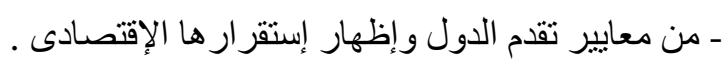

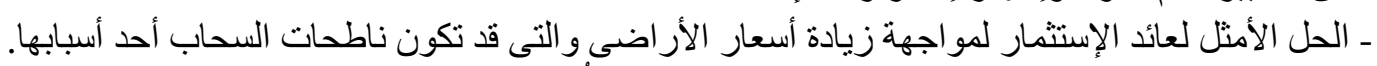

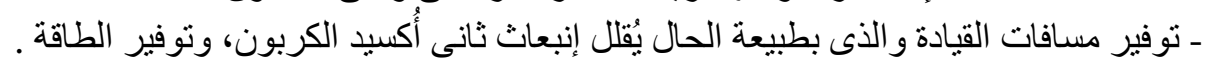

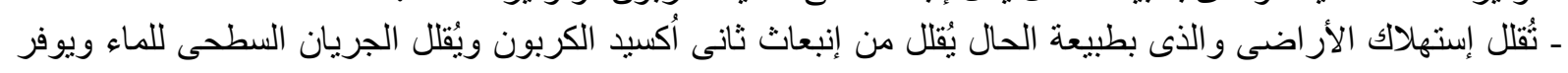

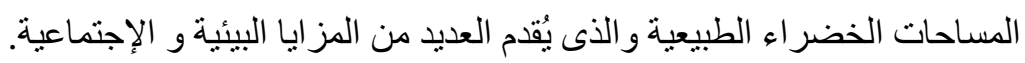

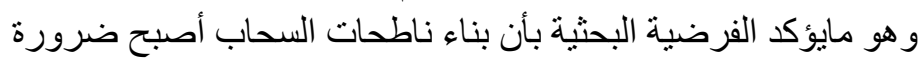

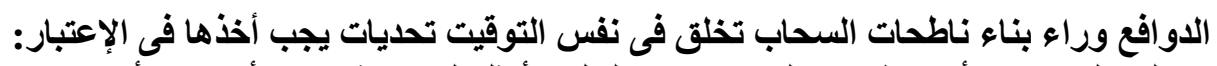

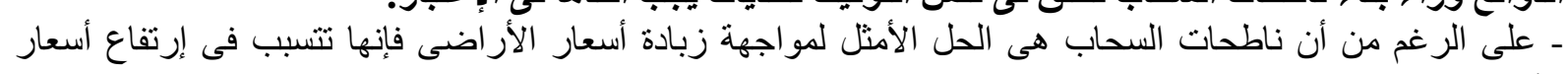
الأر اضى.

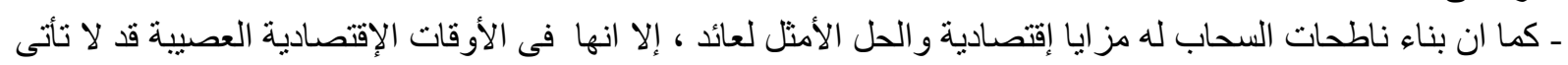

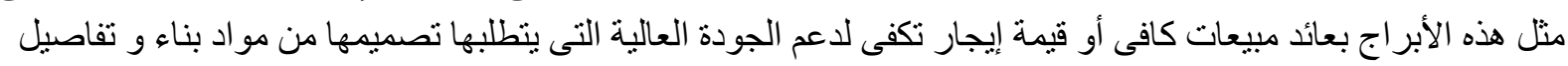

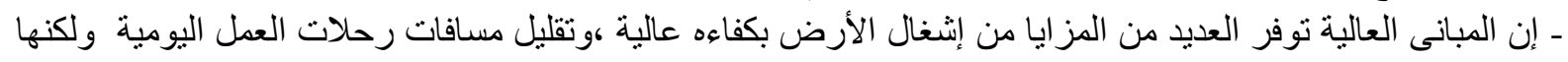


ـ على الرغم من أن ناطحات السحاب يُمكنها أن تؤثر على الصورة العامة للمدينة وتُقدم مشاهد مُتنتو عة للمدينة من أعلى إلا

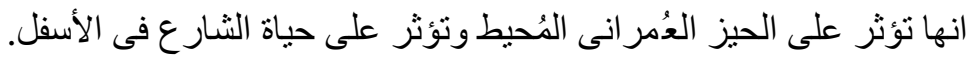

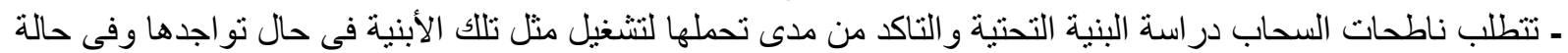

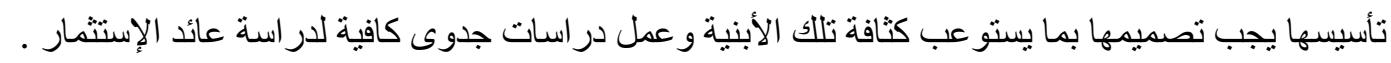
التوصيات : التيات

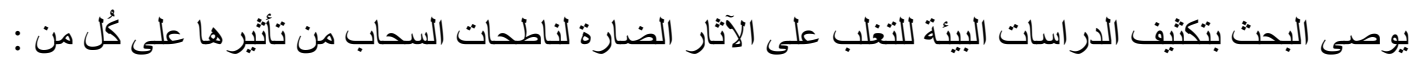

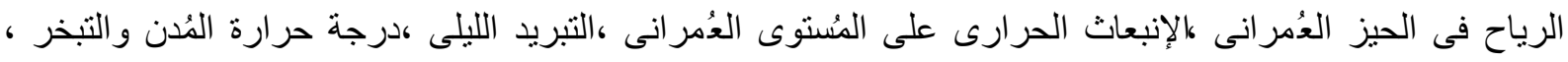

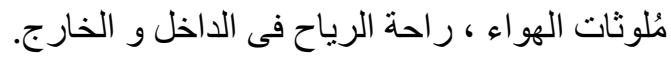

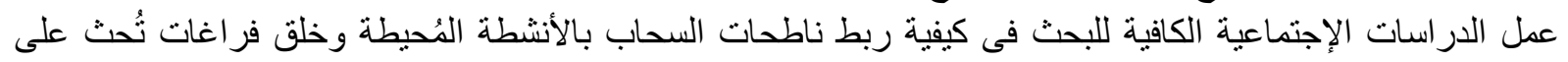

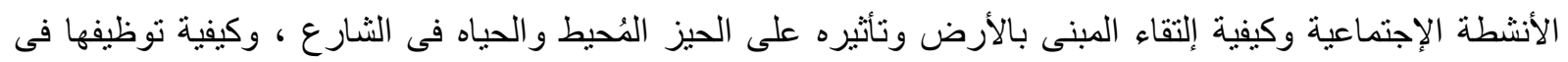
السياق التاريخى للحيز العُمر انى الأحُحيط.

\section{REFERENCES}

1. Aldeberky, A. (n.d.). The influence of high-rise buildings on the environment . Fine Arts

2. College, Menia University, Egypt.

3. Ali, M. (2005). The skyscraper:epitome of human aspirations.Proc.of the 7th CTBUH World Cong .on Tall Buildings and Urban Habitat:Renewing the Urban Landscape. New York ,pp.1 10.

4. Ali, M. (2010). Sustainable Urban Life in skyscraper cities of the 21th century, the sustainable city VI : Urban regeneration and sustainability, eds, C.A. Brebbia, S.Hernandez \& E, Tiezzi. UK: WIT Press:Southampton.

5. Al-kodmany, K. (June 2012). The Logic of Vertical Density:Tall Buildings in the 21st Century. Vol1,No2,( Urban planning and Policy Department,University of Illinois,Chicago.60607,USA).

6. Audretsch, D. (2008). Agglomeration and Location of innovative activity .Oxford Review of Economic Ploicy ,14(2) ,pp. 18 29.

7. Bascomb, N. (2003). A Historic Race to the Sky and the Making of a city, Doubleday. New York.

8. Beedle, 1. A. (2007). The Skyscraper and the City, Design ,Technology, and Innovation , . NY: Edwin Mellen Press: Lewiston.

9. Dalton, K. a. (2008). Towards more sustainable tall buildings . Proc. of the 8th CTBUH World Cong. On Tall \& Green: Typology for Sustaiable Urban Future,ed. A. Wood, CD-ROM.

10. Ellis, P. P. (2005, August 15-18). Simulating tall buildings using energyplus . Proc . of the 9th Int .IBPSA Conf. on Building Simulation ,. Montreal ,Canada.

11. EEwing, R. W. (2008). Growing Cooler: Evidence on Urban Development and climate change. . Washington D.C.: The Urban Land Institute.

12. Guthrie, A. (2008). tall buildings sustainability from the bottom up . Proc. of the 8th CTBUH world Cong . on Tall \& Green : Typology for a Sustainable Urban Future, ed . A. Wood , CD-ROM , pp. 95 101.

13. LS Beedle, M. M. (2007). The Skyscraper and the City: Design, Technology, and Innovation. Lewiston, NY: The Edwin Mellen Press..

14. Merghani, A. (2002). Control of wind- blown sand and dust by town planning and building design, Urban Development in Arid Regions \& Associated Problems. KSA: Ministry of Public Work \& Housing Conference.

15. Murphy, T. M. (2008). Urban Land Green, The Urban land Institute . Washington DC.

16. Owen, D. (2009). Green Metropolis:Why Living Smaller, Living Closer, aand Driving Less are the Keys to sustainability. New York: Riverhea Books, Penguin Group..

17. Riley, T. (2003). Tall Buildings, The Museum of Modern Art ,New York ,NY.

18. Seabrook, J. ( November 19, 2001). The Tower Builder, Why did the World Trade Center buildings fall down when they did? The New Yorker .

19. Sonder, B. (n.d.). Skyscrapers. New york:Metro Books: Michael Friedman.

20. Yeang, K. (2008). Ecoskyscrapers and ecomimesis:new tall building typologies.Proc:of the 8th CTBUH world Cong.on Tall \&Green :Typology for Sustainblilty

Websites: 


$$
\text { الدافع وراء بناء ناطحات السحاب و التحديات التى تو اجهها }
$$

21. (Buchanan, C. (2008). The economic impact of high density development andd tall buildings in central business districts, a report for the BPF, British Property Fedration,pp.1 43,September,http://www.ctbuh.org

22. Buntin, J. (2011, يوليو). Economic evelopment. Retrieved 20, 2015, from Governing: http://www.governing.com/topics/economic

23. Fader, N. S. (2008). Green skyscrapers:What is being built and why? a report for CRP 3840:Green Cities, December 4. http://courses.cit.cornell.edu.

24. McKenzie, W. (2014, November 17). Postpolitical Infrastructures. Retrieved from PUBLIC SEMINAR: http://www.publicseminar.org.

25. UnitedNations. (2011). World Urbaniztaion Prospects:The 2007 Revision Population Database.esa.un.org/unnp/retrived July 30.

26. Watts, S. M. (2007). The economics of supertall towers. The structural Design of Tall and Special Buildings 16,pp.457 470.

27. Wood, A. (2011). Best Tall Buildings 2010, CTBUH international Award Winning Projects , Councile on Tall Buildings and Urban Habitat (CTBUH)\Rotledge. New York, NY.

28. world., T. W. (2008, November 25). The World's Tallest Buildings: Timeline of all skyscrapers holding the title of tallest buildings in the world. . Retrieved from

www.skyscraper.org/TALLEST_TOWER/tallest.htm 